\title{
An Effective Utilization of Solar Energy: Enhanced Photodegradation Efficiency of $\mathrm{TiO}_{2} /$ Graphene-Based Composite
}

\author{
Peipei Huo ${ }^{1}{ }^{(\mathbb{D}}$, Peng Zhao ${ }^{2}$, Yin Wang ${ }^{3}$, Bo Liu ${ }^{1, *}$ and Mingdong Dong ${ }^{3, *(\mathbb{D})}$ \\ 1 Laboratory of Functional Molecules and Materials, School of Physics and Optoelectronic Engineering, \\ Shandong University of Technology, Xincun West Road 266, Zibo 255000, China; peipeihuo@sdut.edu.cn \\ 2 School of Materials Science and Engineering, Shandong University of Technology, Xincun West Road 266, \\ Zibo 255000, China; 16509140463@stumail.sdut.edu.cn \\ 3 Interdisciplinary Nanoscience Center (iNANO), Aarhus University, DK-8000 Aarhus C, Denmark; \\ yin.wang@post.au.dk \\ * Correspondence: liub@sdut.edu.cn (B.L.); dong@inano.au.dk (M.D.)
}

Received: 6 February 2018; Accepted: 9 March 2018; Published: 12 March 2018

\begin{abstract}
The integration of graphene-based material and $\mathrm{TiO}_{2}$ can greatly enhance the photodegradation efficiency toward contaminants in the environment. As the morphology of $\mathrm{TiO}_{2}$ varies from a 0D nanoparticle (NP) and a 1D Nanotube (NT)/Nanowire (NW) to a 2D nanosheet, the contact between $\mathrm{TiO}_{2}$ and graphene-based material would increasingly intensify and the distribution of $\mathrm{TiO}_{2}$ on the graphene sheets becomes more uniform. Both factors lead to better photocatalytic performance. The graphene commonly possesses the intrinsic properties of higher surface area, more efficient charge transfer, inhibited electron-hole pairs (EHPs)' recombination and extended light absorption range. With the assistance of some functional surfactants, the photodegradation performance can be further improved according to more specific requirements such as the photodegradation selectivity. This paper provides an overview of recent progress regarding the method and mechanism of graphene in various $\mathrm{TiO}_{2} /$ Graphene composites.
\end{abstract}

Keywords: $\mathrm{TiO}_{2} /$ Graphene composite; photocatalysis; electron-hole pair; photodegradation

\section{Introduction}

In the modern scenario of research interests, solutions to climate change and the greenhouse effect appear to be the most investigated field in the scientific community, which can be attributed to the burning of fossil fuels. Innovations to convert from fossil fuels to sustainable and renewable energy sources such as wind, solar, wave and biomass is a high priority. Among these energy sources, solar energy stands out as a favorable choice because it has applications in a broad range of fields such as solar photovoltaic, waste water treatment, solar water heating, etc. Photocatalysis, based on sustainable utilization of a semiconductor and solar energy, is regarded as one of the ideal green solutions to the global energy crisis and environmental deterioration. Almost all of the organic contaminants in the environment can be degraded by photocatalysts with no waste resources or additional pollution. In a typical photocatalytic process, semiconductors can absorb and utilize solar energy because of their featured electronic structure as filled valence band (VB) and empty conduction band (CB). Upon solar light irradiation with energies superior to band gap, electrons will be excited from VB to $\mathrm{CB}$, thus leaving holes in VB. The photogenerated holes and electrons can be utilized to oxidize organic contaminants or reduce water, respectively. Such an innovative way of utilizing solar energy to photocatalyze chemical reactions is effective, low cost and most importantly, environmentally benign.

Among lots of semiconductors that can be employed to photodecompose organic pollutants, titanium dioxide $\left(\mathrm{TiO}_{2}\right)$ has been one of the functional materials that are intensively studied, based on 
its application in the degradation of contaminants in the environment [1-4]. $\mathrm{TiO}_{2}$ possesses several benefits, including being a low cost, abundant resource with long term stability, non-toxicity and photocorrosion resistance. On the contrary, the photocatalytic performance of $\mathrm{TiO}_{2}$ is largely restricted by the wide band gap up to $3.2 \mathrm{eV}$ for the anatase phase, which can only be overcome by the UV light. Upon irradiation, photogenerated EHPs are formed, that are intensively involved in the subsequent photocatalytic reactions. Nonetheless, the EHPs have an extremely short recombination time on the order of $10^{-9} \mathrm{~s}$, which have an adverse effect on photocatalysis. Shortly speaking, $\mathrm{TiO}_{2}$ is susceptible to adverse charge carrier recombination and low solar energy utilization efficiency. One important strategy among the many proposed solutions is to utilize metal or nonmetal doping into $\mathrm{TiO}_{2}$ [5-8]. This strategy effectively inhibits the recombination of EHPs and extends the photoresponsive light absorption region. Based on this understanding, composites of graphene and $\mathrm{TiO}_{2}$ have shown favorable enhancement of photocatalytic efficiency in a lot of studies because of the efficient way in which graphene can transfer charge carrier.

There have been reports on the composites of $\mathrm{TiO}_{2}$ and various carbon allotropes, which are able to exhibit more enhanced photocatalytic performance compared to bare $\mathrm{TiO}_{2}$. Graphene, as a shining star of carbon allotropes, owns many unique features. Its two-dimensional lamellar structure endows itself with promising thermal, mechanical, electrical and optical properties. These novel and beneficial properties are utilized in synthesizing graphene-based materials for a variety of technological applications such as nanoelectronics, $\mathrm{H}_{2}$ production and storage, supercapacitors and catalysis. Incorporation of graphene with $\mathrm{TiO}_{2}$ would generate a hybrid nanocomposite that integrates desirable properties of each component for targeted applications [9-15]. Consequently, the photocatalytic efficiency of $\mathrm{TiO}_{2}$ will be improved.

Many cases have indicated that graphene can significantly enhance the photodegradation of pollutants compared to bare $\mathrm{TiO}_{2}$. To this purpose, recent progress regarding the method and mechanism in $\mathrm{TiO}_{2} /$ Graphene composite is summarized in this review (Table 1). Based on the morphology and constituents in the composite, the review is divided into three main sections. Section 2 introduces $\mathrm{TiO}_{2} /$ Graphene composite with various dimensional morphologies. A series of dimensional morphology will be presented, from OD NP to a 3D hierarchical nanosphere. Different morphology will cause the change of electron conductivity and reactant absorptivity in the composite. Section 3 focuses on $\mathrm{TiO}_{2} /$ Graphene composite with novel construction or additives. Several surfactant or functional molecules are introduced in the composite to either assist in shaping a novel structure or bringing new features to enhance photoactivity. Section 4 summarizes the common conclusion on the mechanism of graphene-enhanced photodegradation efficiency.

In principle, graphene is a two-dimensional sheet of graphite arrayed hexagonally with monolayer thickness. One fact that needs attentions is that there are ambiguities going through the research references on the nomenclature of graphene and its derivative materials. A certain number of "graphene" referred in the research articles possess actually multiple stacking layers and gradually the term "graphene" has extended to misleadingly stand for a wide range of graphene's derivatives. It is necessary that a consistent nomenclature is designated and was the theme of another article [16]. This current paper applies the nomenclature regarding graphene terms proposed by the above authors, of which the relevant contents are listed in Table 2. In fact, the term "graphene" should be defined as the isolated monolayer with carbon atoms bonded in the $\mathrm{sp}^{2}$ configuration, forming a hexagonal arrangement. The term "Graphene oxide" (GO) refers to the exfoliated form of graphite oxide. Reduced graphene oxide ( $\mathrm{rGO}$ ) means the reduction of GO. We refer to the many derivatives of the graphene family, in this current paper, as "graphene-based materials". 
Table 1. Characterizations of $\mathrm{TiO}_{2} /$ Graphene photocatalysts and their photodegradation performance.

\begin{tabular}{|c|c|c|c|c|c|c|}
\hline $\begin{array}{l}\text { [Ref.] Catalyst } \\
\text { Abbreviation }\end{array}$ & $\begin{array}{l}\text { Chemical to Be } \\
\text { Degraded }\end{array}$ & Photocatalytic Activity & $\begin{array}{l}\text { Surface Area } \\
\left(\mathrm{m}^{2} / \mathrm{g}\right)\end{array}$ & Light Source & Band Gap (eV) & Active Radical \\
\hline [17] $\mathrm{TiO}_{2} /$ Graphene & Benzene \& MB & much higher than that of bare $\mathrm{TiO}_{2}$ & & $\begin{array}{l}\text { UV\& visible light(with a UV } \\
\text { cutoff filter, } \lambda>400 \mathrm{~nm} \text { ) }\end{array}$ & 2.83 & $\begin{array}{l}\text { hydroxyl radical \& } \\
\text { superoxide redical }\end{array}$ \\
\hline$[18] \mathrm{TiO}_{2} / \mathrm{rGO}$ & Arsenite & much the same as $\mathrm{Pt} / \mathrm{TiO}_{2}$ & 51.9 & $\lambda \geq 320 \mathrm{~nm}$ & & $\begin{array}{l}\text { superoxide \& } \mathrm{OH} \\
\text { radicals }\end{array}$ \\
\hline [19] TGH & MB & $\begin{array}{l}\text { complete degradation within } 30 \\
\text { min }\end{array}$ & 267.98 & $\mathrm{UV}$, centered at $365 \mathrm{~nm}$ & & \\
\hline$[20] \mathrm{TiO}_{2} / \mathrm{rGO}$ & MB & $\begin{array}{l}\text { photothermal effect contributes } \\
\sim 38 \% \text { degradation }\end{array}$ & & $\begin{array}{l}\text { xenon lamp with a } 720 \mathrm{~nm} \\
\text { short-path filter } \\
\text { and a } 720 \mathrm{~nm} \text { long pass filter }\end{array}$ & & \\
\hline [21] $\mathrm{TiO}_{2} / \mathrm{GO}$ & MO & improved performance than $\mathrm{P} 25$ & & $\lambda>400 \mathrm{~nm}$ & 2.43 & \\
\hline [22] $\mathrm{TiO}_{2} / \mathrm{GO}$ & RhD B & $\begin{array}{l}\text { a three-fold photocatalytic } \\
\text { enhancement over P25 }\end{array}$ & 190 & mercury lamp & & \\
\hline$[23] \mathrm{TiO}_{2} / \mathrm{GO}$ & MB & $\begin{array}{l}92 \% \mathrm{MB} \text { degraded after } 110 \mathrm{~min} \\
\text { irradiation }\end{array}$ & & mercury lamp & & \\
\hline [24] $\mathrm{TiO}_{2} / \mathrm{rGO}$ & RhD 6G & $\begin{array}{l}\text { more than triple higher } \\
\text { photodegradation rate than P25 }\end{array}$ & & mercury lamp $\lambda>400 \mathrm{~nm}$ & 2.71 & $\bullet \mathrm{OH}$ radicals \\
\hline [25] $\mathrm{TiO}_{2}$ spindle/rGO & MG & $\begin{array}{l}\text { a } 6 \text { fold increase in efficiency over } \\
\text { the native } \mathrm{TiO}_{2} \text { cube }\end{array}$ & 89.34 & mercury lamp $\lambda \geq 420 \mathrm{~nm}$ & 2.91 & \\
\hline [26] $\mathrm{TiO}_{2} \mathrm{NW} / \mathrm{GO}$ & MB & $\begin{array}{l}\text { much higher than } \mathrm{TiO}_{2} \mathrm{NP} / \mathrm{GO} \\
\text { and pure } \mathrm{TiO}_{2} \mathrm{NWs} \text { or NPs }\end{array}$ & & solar light & & \\
\hline $\begin{array}{c}{[27]} \\
\mathrm{TiO}_{2} \text { nanosheet/Graphene }\end{array}$ & $\begin{array}{c}\mathrm{RhD} \mathrm{B} \mathrm{\&} \\
\text { 2,4-dichlorophenol }\end{array}$ & $95 \%$ dyes degraded within $60 \mathrm{~min}$ & & $\begin{array}{l}\text { mercury lamp centered at } \\
\qquad 365 \mathrm{~nm}\end{array}$ & & $\bullet \mathrm{OH} \& \mathrm{O}_{2} \bullet-$ \\
\hline [28] $\mathrm{TiO}_{2}$ nanosheet/rGO & MB & higher than that of $\mathrm{TiO}_{2}$ & & mercury lamp & & $\bullet \mathrm{OH}$ radicals \& holes \\
\hline $\begin{array}{l}\text { [29] } \mathrm{TiO}_{2} \text { hollow } \\
\text { sphere/GO }\end{array}$ & RhD B & $95 \%$ degraded within $60 \mathrm{~min}$ & & mercury lamp & 2.51 & hydroxyl radicals \\
\hline [30] $\mathrm{TiO}_{2} /$ Graphene & MB \& estradiol & $\begin{array}{l}2 \text { fold higher photocatalytic } \\
\text { activity than } \mathrm{TiO}_{2}\end{array}$ & & $\begin{array}{c}\text { xenon lamp, centered at } \\
350 \mathrm{~nm}\end{array}$ & 2.95 & \\
\hline
\end{tabular}


Table 2. Nomenclature used for graphene family materials.

\begin{tabular}{ccl}
\hline Material & Abbreviation & \multicolumn{1}{c}{ Formulation } \\
\hline graphene & & $\begin{array}{l}\text { two-dimensional sheet of graphite arrayed } \\
\text { hexagonally with monolayer thickness }\end{array}$ \\
\hline graphite oxide & & $\begin{array}{l}\text { oxidized graphite with oxygen functional groups on } \\
\text { the basal planes and increased interlayer spacing }\end{array}$ \\
\hline graphene oxide & GO & exfoliated form of graphite oxide \\
\hline reduced graphene oxide & rGO & $\begin{array}{l}\text { reduced form of graphene oxide via a chemical, } \\
\text { thermal, solvothermal etc. process }\end{array}$ \\
\hline
\end{tabular}

\section{2. $\mathrm{TiO}_{2} / \mathrm{Graphene}$ Based Materials with Various Dimensional Morphologies}

\section{1. $0 \mathrm{D} \mathrm{TiO}_{2} \mathrm{NP} / 2 \mathrm{D}$ Graphene/GO/rGO Sheet}

\subsubsection{Graphene/GO/rGO Sheet-Spherical $\mathrm{TiO}_{2} \mathrm{NPs}$}

Graphene has many unique features, such as high electron mobility, theoretically high surface area and good mechanical strength. Therefore, it is a plausible assumption that the integration of $\mathrm{TiO}_{2}$ with graphene could lead to a much improved photocatalytic performance compared with bare $\mathrm{TiO}_{2}$. Graphene oxide (GO) has a surface decorated with oxygenated functional groups, which provides efficient binding sites for $\mathrm{TiO}_{2}$. The introduction of $\mathrm{GO}$ can act as an electron scavenger and subsequently transport the electrons in an efficient pathway. In addition, the existence of GO enhances the capacity of the hybrid for the physisorption, as well as the chemical adsorption, of degradable molecules. Many cases indicate the photocatalytic effect of $\mathrm{TiO}_{2} /$ Graphene composite. Hiskia et al. reported that, under solar light irradiation, $\mathrm{TiO}_{2} / \mathrm{GO}$ presented the same level of photocatalytic activity with commercialized $\mathrm{TiO}_{2}$ powders (Degussa P25) [31]. Likewise, $\mathrm{Xu}$ et al. have fabricated the nanocomposites of $\mathrm{TiO}_{2} /$ Graphene with a series of weight ratios of graphene via a hydrothermal treatment. The as-made $\mathrm{TiO}_{2} /$ Graphene nanocomposites were utilized to photocatalyze the degradation of gas-phase benzene, a volatile organic pollutant (VOC) in air. It was demonstrated that the photocatalytic activity decreased with the weight ratio of graphene [17]. The similar phenomenon was reported by $\mathrm{Choi}$ et al. They fabricated a $\mathrm{TiO}_{2}$-based nanocomposite coupled with reduced graphene oxide (rGO), which led to an efficient photocatalytic oxidation of As(III). The investigation of competitive radical quenchers confirmed that As(III) photocatalytic oxidation was carried out through both superoxide and $\mathrm{OH}$ radicals [18]. Bahamode et al. demonstrated the $\mathrm{TiO}_{2} / \mathrm{GO}$ composite they prepared with a significantly improved photocatalytic activity with respect to $\mathrm{TiO}_{2} \mathrm{P} 25$ under visible light. A shorter reaction time for photodegradation of $50 \%$ pesticides and higher chloride formation rate were achieved with $\mathrm{TiO}_{2} / \mathrm{GO}$ [32].

Besides the above-mentioned role of graphene as scavenger and transfer media for electrons, GO has the ability to form a 3D structure through various connections including hydrogen bonding, electrostatic force and $\pi-\pi$ electron coupling. Liu et al. fabricated a $\mathrm{TiO}_{2} \mathrm{NPs}$-graphene hydrogel (TGH) (Figure 1) by a hydrothermal process. The as-prepared TGH possessed 3D interconnected networks and high surface area, which displayed a synergistic effect of the self-assembled $\mathrm{TiO}_{2} \mathrm{NPs}$ and graphene nanosheets. The 3D structure of TGH could significantly enhance the adsorption capacity including physical adsorption and the aromatic dye's adsorption on the surface of graphene via $\pi-\pi$ electron coupling. In addition, the 3D graphene networks could transfer electrons efficiently, leading to a significantly improved photocatalytic activity of methylene blue (MB) (Figure 1d) [19].

On the specific function of graphene in photoresponse, Wu et al.'s work clarified that the assumption of up-converted photoluminescence (PL) from rGO excited by noncoherent light was artificial [33]. Therefore, it is disputable to attribute enhanced photocatalytic degradation to the up-converted PL. Except the three common traits of rGO in the process of graphene-based 
semiconductor photocatalysis, which are trapping and transferring of photogenerated charges, increasing adsorption of contaminants and extending light absorption, $\mathrm{Wu}$ et al. proposed that the strong photothermal effect (PTE) of rGO is another essential factor influencing the photocatalytic performance. In the study on the degradation of $\mathrm{MB}$, the contribution coming from the PTE in the $\mathrm{P} 25 / \mathrm{rGO}$ nanocomposite can be as high as $38 \%$ except the common advantages of rGO, as shown in Figure 2b,c. Near infra-red irradiation heats up the rGO sheets because of PTE, which renders a faster movement of electrons with more energy on the hot rGO sheets. As a result, PTE facilitates the photodegradation of contaminants in the $\mathrm{TiO}_{2} / \mathrm{rGO}$ nanocomposites. Their work indicates that the PTE is of crucial importance in the photocatalysis by graphene-based nanocomposite [20].
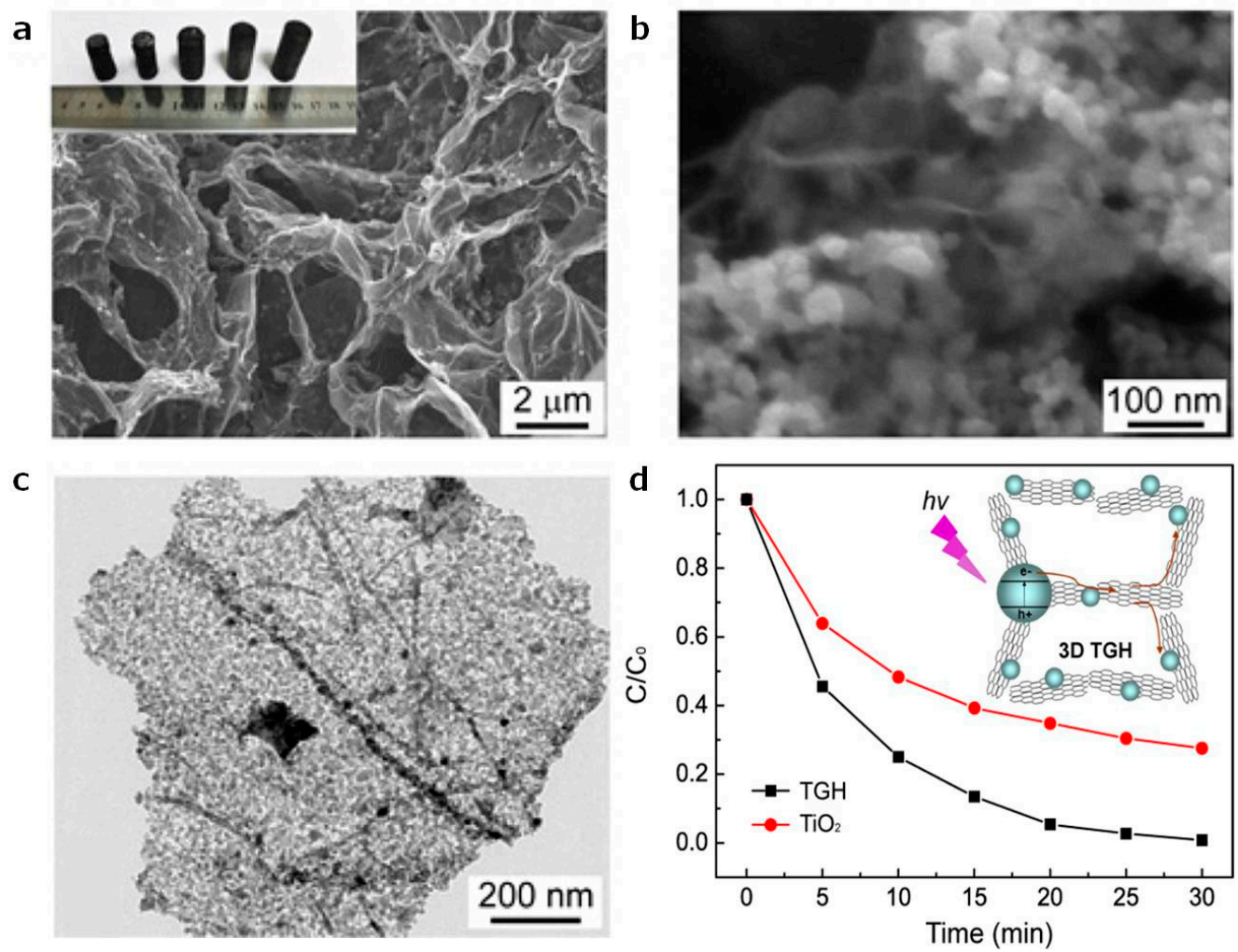

Figure 1. Low- and high-magnified SEM images of TGH $(\mathbf{a}, \mathbf{b})$, inset of $(\mathbf{a})$ is the photograph of TGH with a different ratio of $\mathrm{TiO}_{2}$ to graphene, (c) low-magnified TEM images of TGH. (d) relative changes of the adsorption peak intensity as a function of irradiation time in the presence of TGH and $\mathrm{TiO}_{2}$ nanoparticles. Inset is the schematic diagrams for illustrating the charge transfer behavior at interfaces in 3D TGH networks. (Reprint from [19] with permission from the American Chemical Society. Copyright 2013).

Normally, the oxidation of graphene can open an electron energy gap, of which the value is determined by the oxidization degree and species of oxygen-containing groups. In this regard, GO could tune its electron conductivity by changing the oxidation degree, which leads to a diverse energy gap and structure distortion and then renders various chemical properties of graphene. Cai et al. studied the influence of the concentration of GO on the photocatalytic activity of $\mathrm{TiO}_{2} / \mathrm{GO}$ composite. When the $\mathrm{TiO}_{2} / \mathrm{GO}$ hybrid was used to decolorize methyl orange (MO), it was excited by visible light irradiation $\left(>400 \mathrm{~nm}\right.$ ), that is, both $\mathrm{TiO}_{2}$ and semiconductor formed by GO could be excited. It was concluded that a narrow band gap as $2.43 \mathrm{eV}$ in the semiconductor formed by GO was a key factor in the photocatalytic activity of the $\mathrm{TiO}_{2} / \mathrm{GO}$ hybrid. To be more specific, the p-type semiconductor formed by GO in hybrid with a lower carbon weight ratio in the range of $0.13-0.15 \mathrm{wt} \%$ may function as a sensitizer to enhance the photocatalytic performance. Otherwise, higher carbon element changes the GO to an n-type semiconductor and the photocurrent generated was negligible 
and the enhancement of photocatalytic performance was not obvious. Their work suggests a possibility of tuning photocatalytic performance by varied $\mathrm{C} / \mathrm{O}$ ratio in the initial compositions of solution [21].
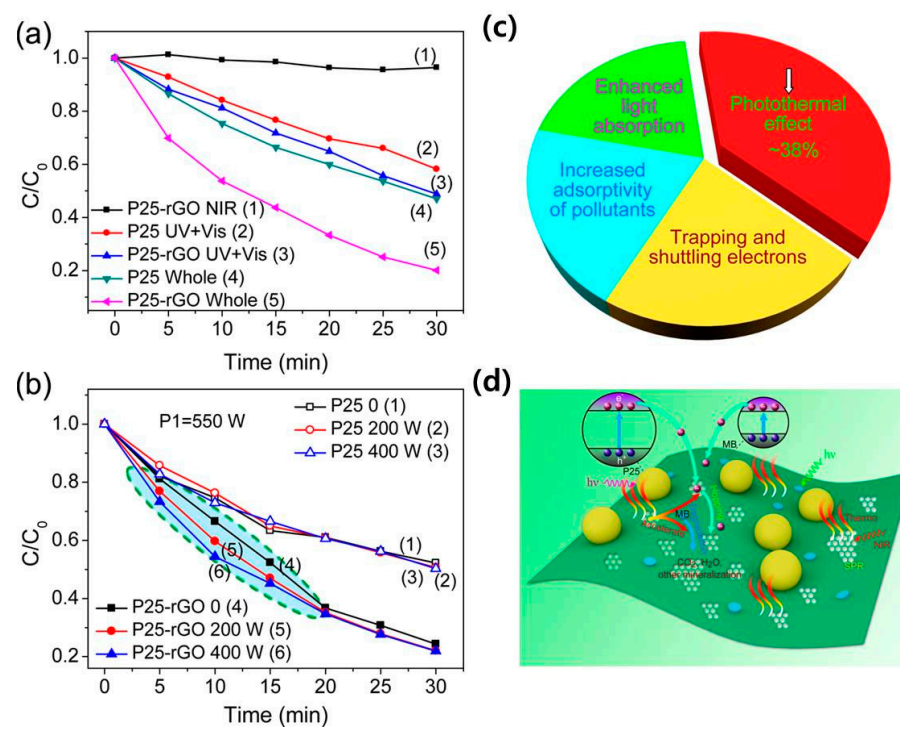

(d)

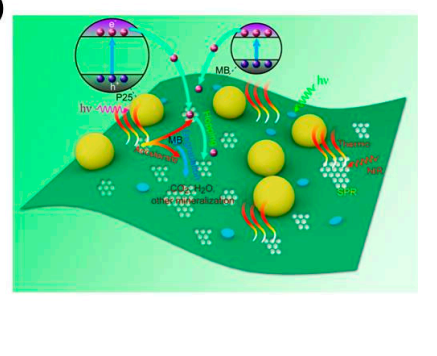

Figure 2. (a) Photocatalytic degradation of MB on P25 or P25-rGO; (b) photocatalytic degradation illuminated by two lamps, lamp 1 with a fixed power provides light in the whole wavelength range and the power of lamp 2 (NIR) is varied; (c) contribution of graphene in the enhanced photocatalytic activity; (d) mechanism of MB degradation over P25-rGO (Reprint from [20] with permission from the American Chemical Society. Copyright 2014).

The $\mathrm{TiO}_{2}$ nanocrystal growth on graphene sheets is another interesting aspect of $\mathrm{TiO}_{2} / \mathrm{Graphene}$ hybrid research. By controlling nucleation and growth, $\mathrm{TiO}_{2}$ nanocrystals with exposed high active facets could favorably bond to and interact with graphene sheets, thus strengthening the electrical and mechanical coupling within the hybrid. By controlling the rate of hydrolysis, Dai et al. made almost $100 \%$ of the $\mathrm{TiO}_{2}$ nanocrystal grow specifically on the GO sheets, with negligible growth of free $\mathrm{TiO}_{2}$ nanocrystal in the aqueous solution. The as-prepared hybrid showed remarkably higher photocatalytic activity than other forms of $\mathrm{TiO}_{2}$ including $\mathrm{TiO}_{2}$ powders and physical mixture of $\mathrm{TiO}_{2}$ and GO [22]. To supplement the observation, as exposed high reactive facets can facilitate more active photocatalytic reaction, a $\mathrm{TiO}_{2} /$ Graphene hybrid with exposed $\{001\}$ facets was prepared by Wang et al. Fabricated via a solvothermal process assisted by the methanol and hydrofluoric acid, the $\mathrm{TiO}_{2} /$ Graphene composites exhibited a superior photocatalytic activity than P25 under UV light [34].

In order to be environmentally benign, Yoo et al. synthesized $\mathrm{TiO}_{2}-\mathrm{rGO}$ nanocomposites using a one-step hydrothermal method, with no requirements for toxic solvents or chemicals as a reducing agent for GO. The resulting $\mathrm{TiO}_{2} / \mathrm{rGO}$ nanocomposites displayed good photocatalytic activity toward the degradation of Rhodamine $\mathrm{B}(\mathrm{RhD} B)$ dye under visible light irradiation. In addition, the photocatalytic activity increased with decreasing ratio of rGO in composites [35]. Other endeavors in environmental management include GO membrane separation technology. GO can work as a membrane material due to its good mechanical strength, ultrathin layered structure, excellent flexibility and outstanding separation performance. However, the membrane fouling of GO based membranes is limiting its large-scale application. By photocatalyzing GO membranes, the fouling components-mainly from organic pollutants—can be efficiently removed. Therefore, it is desirable to design a $\mathrm{TiO}_{2} / \mathrm{GO}$ composite membrane which can both solve the fouling problem of GO-based membrane and enhance the photocatalytic activity of $\mathrm{TiO}_{2}$ semiconductor. $\mathrm{TiO}_{2} \mathrm{NPs}$ were in situ grown on the GO sheets and the subsequent UV-light treatment can cause more distinctive wrinkles on the sheet surface, which facilitates molecular transportation. The as-made $\mathrm{GO} / \mathrm{TiO}_{2}$ membrane was utilized in a cross flow filtration process, which displayed outstanding photocatalytic performance 
in degradation of MB under UV light. The membrane fouling was efficiently removed with UV light irradiation, leading to a high ability of flux recovery (96\%) after $100 \mathrm{~min}$ [23].

In 2008, Kamat et al. reported that UV light could be used to effectively reduce GO sheets without a requirement for other reducing chemicals. In the meanwhile, the $\mathrm{TiO}_{2} / \mathrm{Graphene}$ composites were simultaneously synthesized with the reduction process going. Likewise, Wei et al. synthesized $\mathrm{TiO}_{2} /$ rGO composites through a facile, reducing chemical-free and UV-assisted photoreduction pathway. By tuning the GO ratio in starting solution and time length of UV irradiation, the dependence on the reduction degree of GO for the photocatalytic activity was investigated. The as-prepared $\mathrm{TiO}_{2} / \mathrm{rGO}$ composites displayed better performance in photodegradation of rhodamine $6 \mathrm{G}(\mathrm{RhD} 6 \mathrm{G})$ than the commercial P25 NPs. The better performance of $\mathrm{TiO}_{2} / \mathrm{rGO}$ composites was ascribed to the beneficial synergistic effect of graphene and $\mathrm{TiO}_{2} \mathrm{NPs}$. Beside the common features introduced by graphene, the authors provided several other reasons for activity enhancement. 1. The hydrophilic nature of the functional groups on $\mathrm{rGO}$ made $\mathrm{TiO}_{2} / \mathrm{rGO}$ composite disperse well in the liquid phase; 2. Strong interaction between the components prevented $\mathrm{TiO}_{2}$ from leaching out; 3 . The efficient desorption of product decomposed from $\mathrm{RhD} 6 \mathrm{G}$ due to the strong oxidization ability of free $\bullet \mathrm{OH}$ radicals results in an efficiently recovered graphene surface and the active sites [24].

The above research about $\mathrm{TiO}_{2} /$ Graphene for catalytic degradation of organic pollutants focus on photon-excited degradation. However, the study concerning $\mathrm{TiO}_{2} / \mathrm{rGO}$ as a non-light-driven advanced oxidation processes (AOP) catalyst is a rare case. Wang et al. have developed a facile hydrothermal procedure to synthesize $\mathrm{TiO}_{2} \mathrm{NPs}$ and graphene composites. The as-prepared nanocomposite can be used as effective non-light driven catalysts for activating $\mathrm{H}_{2} \mathrm{O}_{2}$ in oxidative degradation of $\mathrm{MB}$ in dark thermal reaction. Using $\mathrm{H}_{2} \mathrm{O}_{2}$ as an intermediate, $\mathrm{MB}$ was effectively degraded by $\mathrm{TiO}_{2} / \mathrm{rGO}$ without any light and only $4 \%$ of initial MB remained in the solution after $1 \mathrm{~h}$. The mechanism investigation revealed that $\bullet \mathrm{OH}$ radicals played a key role in the oxidation pathway [36].

\subsubsection{Spindle-Like $\mathrm{TiO}_{2} \mathrm{NP} / \mathrm{Graphene} / \mathrm{GO} / \mathrm{rGO}$ Sheet}

Spindle-like $\mathrm{TiO}_{2} \mathrm{NP}$ is another interesting structure in the $\mathrm{TiO}_{2} / \mathrm{Graphene}$ composites. Devi et al. demonstrated the conversion of $\mathrm{TiO}_{2}$ anatase nanocube to anatase nanospindle, while maintaining the bonding between $\mathrm{TiO}_{2}$ and graphene. The as-formed $\mathrm{TiO}_{2}$ nanospindle exposed both $\{001\}$ and $\{101\}$ facets. The shape transition occurs as a function of reaction duration using $\mathrm{TiO}_{2}$ cube/GO suspension as a start via a hydrothermal treatment method. With 5\% GO loading and a 4 h reaction time, the shape transition from nanocubes to nanospindles achieved the maximum limit. $\mathrm{TiO}_{2}$ spindle/rGO displayed outstanding photocatalytic activity with $\sim 6$ times increase compared to respective $\mathrm{TiO}_{2}$ cube, the reason of which was ascribed to the synergistic effect of more exposed $\{001\}$ high energy facets and optimized loading of rGO. The rGO sheets made the photoelectrons more separated from the $\{101\}$ reductive sites and restricted their recombination [25]. A nonstoichiometric spindle-like $\mathrm{TiO}_{2}$ $\mathrm{NP} /$ graphene sheet nanocomposite was prepared by the one-pot thermal hydrolysis of suspension. The direct interaction between $\mathrm{TiO}_{2}$ nanospindles and graphene sheet led to an anti-restacking property of the exfoliated sheets of graphene. The highest photocatalytic activity of $\mathrm{TiO}_{2} / \mathrm{Graphene}$ nanocomposites was achieved with a graphene dopant concentration of $0.002 \%$. The dynamics ceased as an increasing graphene dopant concentration [9].

The above cases suggest that graphene can introduce a series of benefits to the $\mathrm{TiO}_{2}$ photocatalyst, including efficient electron migration, more reactant adsorptive surface area and a narrowed band gap. But there still exists limitation with $\mathrm{TiO}_{2} \mathrm{NP} /$ graphene sheet morphology, due to the fact that $\mathrm{TiO}_{2} \mathrm{NPs}$ are prone to agglomeration, even forming a dense layer, which certainly reduces the photodegradation activity. Therefore, more research interests aim at constructing $\mathrm{TiO}_{2} /$ Graphene composite with more dimensional morphologies.

\section{2. $1 \mathrm{D} \mathrm{TiO}_{2}$ Nanotube (Nanowire)/2D Graphene/GO/rGO Sheet}

$\mathrm{TiO}_{2}$ NPs are susceptible to aggregation and bond poorly to the graphene sheet owing to their almost spherical shape. Compared with $\mathrm{TiO}_{2} \mathrm{NPs}, 1 \mathrm{D} \mathrm{TiO} 2$ nanotubes (TNTs) have much higher 
inner and outer surface area, so as to be rich of active sites. In addition, 1D morphology provides more intimate interfacial contact associated between TNTs and graphene, which should facilitate photogenerated charge separation and subsequently lead to an enhanced photocatalytic activity. Balkus Jr. et al. reported a facile growth of TNTs on rGO sheets via a hydrothermal method. While TNTs were growing on the GO surface, it was observed that GO was simultaneously reduced to rGO. The 1D TNTs on rGO sheets effectively prevented the rGO sheets from agglomeration and made them readily suspending them in aqueous solution. The nucleation and growth of TNTs were assisted by oxygen species on the rGO surface. The as-prepared rGO-TNT composite displayed a much higher photodegradation activity of malachite green (MG) than TNT itself. The optimal loading of rGO was $10 \%$ and the much lower and higher additions of rGO led to decreased photocatalytic activity, regardless of UV or visible light irradiation [37].

Analogous to 1D TNT, graphene-1D $\mathrm{TiO}_{2}$ nanowire (NW) composite (GNW) is an improvement in respect of morphology-related photocatalytic activity. The most distinct advantage using NWs over NPs is that NWs have a closer interfacial contact with graphene sheet, so as to be uniformly grafted onto graphene by simply considering their geometric scenario (Figure 3). Therefore, the photogenerated electron will transfer from $\mathrm{TiO}_{2}$ to graphene through a very efficient pathway, which promises a higher photocatalytic efficiency. Instead of scattering happening frequently in the NP system, the photogenerated electrons in the NW system gain a direct migration path. According to Fan et al.'s work, $\mathrm{TiO}_{2}$ NWs were distributed more uniformly on $\mathrm{rGO}$ than NPs, therefore more NWs have bonded directly to rGO in contrast to the fact that most NPs do not. Furthermore, in the NW system, charge carriers migrate in a linear path, while in the NP system with agglomeration in most cases, migration occurs in a zigzag path. As a result, electron transfer from NW to rGO can be much more efficient than in agglomerated NPs, which restricts the charge carrier recombination in GNW. A significantly improved photocatalytic activity of GNW nanostructure was proved in the photodegradation of $\mathrm{MB}$ under solar light irradiation. A synergistic effect of graphene and 1D NW morphology was proposed to explain the enhanced photodegradation [26]. Based on NW morphology, Li et al. prepared a $\mathrm{N}-\mathrm{TiO}_{2} \mathrm{NWs} / \mathrm{N}$-graphene $\left(\mathrm{N}-\mathrm{TiO}_{2} / \mathrm{NG}\right)$ composite by a hydrothermal process utilizing urea as the nitrogen dopant source. $\mathrm{N}-\mathrm{TiO}_{2} / \mathrm{NG}$ exhibited improved photocatalytic performance under visible light irradiation. The overlap of the $\mathrm{N}_{2 p}$ energy level of $\mathrm{N}$ dopant and the $\mathrm{O}_{2 p}$ (VB maximum) reduces the energy gap an electron needs to surpass to be injected into $\mathrm{CB}$ of $\mathrm{N}-\mathrm{TiO}_{2} / \mathrm{NG}$ [38].

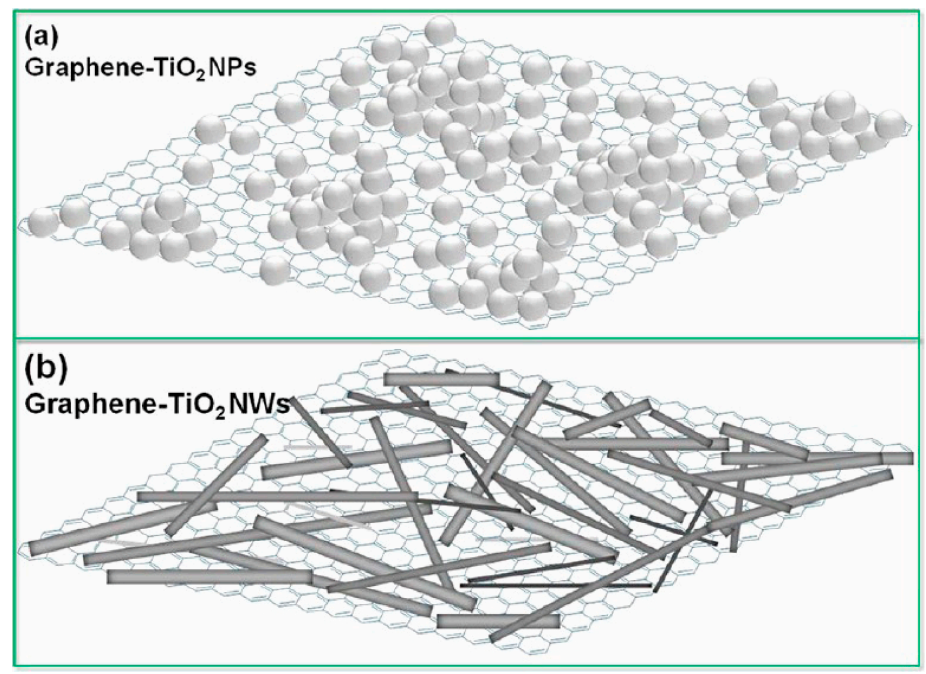

Figure 3. Schematics of (a) $\mathrm{TiO}_{2} \mathrm{NPs}$ agglomerating on graphene sheet and (b) $\mathrm{TiO}_{2} \mathrm{NWs}_{\text {dispersing }}$ uniformly on graphene sheet (Reprint from [26] with permission from the American Chemical Society. Copyright 2012). 


\section{3. $2 \mathrm{D} \mathrm{TiO} \mathrm{T}_{2}$ Nanosheet/2D Graphene/GO/rGO Sheet}

In principle, a 2D-2D heterojunction structure of $\mathrm{TiO}_{2} /$ Graphene composite would favor rapid charge carrier transfer and separation during the photocatalytic process. There were reports of enhanced photoelectrochemical performance because of the stacked $\mathrm{TiO}_{2} /$ Graphene 2D-2D structure. Such 2D-2D layered nanostructures have a maximized contact area between $\mathrm{TiO}_{2}$ and graphene sheets, which shortens the diffusion path of photoinduced charge carriers, thus facilitating rapid electron transfer across the heterojunction interface. Guo et al. synthesized a $\mathrm{TiO}_{2}$ nanosheet/graphene-based 2D-2D photocatalytic system, which possessed an intensified electronic and physical coupling effect, leading to efficient electron transfer process and excellent photocatalytic activity toward the degradation of contaminant molecules [27].

Han et al. presented a solvothermal synthesis of graphene-supported anatase $\mathrm{TiO}_{2}$ sheets. Since rGO sheets can function as a 2D substrate, anatase $\mathrm{TiO}_{2}$ nanocrystals with exposed $\{001\}$ high energy facets grew in situ on the rGO surface, in the form of large area 2D sheets. Simultaneously, with the $\mathrm{TiO}_{2}$ growing on rGO surface, the reduction of GO was successfully achieved. Trapping experiments indicated that the main reason of photocatalytic activity enhancement was attributed to holes left in the $\mathrm{TiO}_{2}$ crystals other than rapid electrons migrating through $\mathrm{rGO}$ [28]. Likewise, $\mathrm{Xu}$ et al. fabricated a $2 \mathrm{D}$ anatase $\mathrm{TiO}_{2}$ nanosheets $/ 2 \mathrm{D}$ graphene large sheet hybrid. The on-top anatase $\mathrm{TiO}_{2}$ nanosheets were dominated with high-energy $\{001\}$ facets as well. Upon visible light irradiation, the as-made nanocomposites exhibited excellent photocatalytic activity. The optimized graphene loading to achieve the highest photocatalytic activity was analyzed to be $1 \% \mathrm{wt}$. The Ti atoms on the flat $\{001\}$ facets are much more exposed, forming sufficient surface defects as oxygen deficiency, which facilitates the interfacial electron transfer and thus effectively separates the photogenerated EHPs. Furthermore, another key factor influencing the enhanced photocatalytic activity is the formation of a chemical Ti-O-C bond, which extends the light absorption band edge to a visible light range [39].

\section{4. $3 \mathrm{D} \mathrm{TiO} \mathrm{T}_{2}$ Hollow Nanospheres/2D Graphene/GO/rGO Sheets}

Out of all kinds of nanostructures developed thus far, hierarchical nanostructures are favorable due to their ability of both light scattering with large particles and providing high surface area with small particles. Increased light scattering causes more efficient light absorption and utilization, while high surface area can absorb more contaminant molecules. Another advance of hierarchical structures is the much improved convenience of removing and recycling of photocatalysts. Micro-sized hollow structures are hierarchical structures with properties of large particles, high surface areas and high light utilization. Dong et al. prepared micro-sized $\mathrm{TiO}_{2}$ hollow spheres (HSs) partially wrapped with rGO bonding through peptide. The hybrid composites were used to reduce 4-nitroaniline (4-NA) under UV and visible light irradiation. A rGO loading with 5\% in the composite led to a higher light absorption and reactant adsorption but lower photocatalytic activity than the corresponding composites with $3 \%$ rGO loading. This is ascribed to the excessive addition of rGO, which partially shields the primary photoactive $\mathrm{TiO}_{2}$, and in the meantime, reduces the exposed available $\mathrm{TiO}_{2}$ 's surface-to-light irradiation [40].

Another $\mathrm{TiO}_{2} /$ Graphene composite with similar structure is reported by Zhang et al. Via a solvothermal method, hollow $\mathrm{TiO}_{2}$ were prepared and subsequently loaded into GO sheet. This hybrid with hierarchical structure was used for the degradation of RhD B under UV and visible light irradiation. The composite exhibited significantly high degradation of $\mathrm{RhD}$ B by $75 \%$ within $3 \mathrm{~h}$, superior to $50 \%$ removal efficiency by hollow $\mathrm{TiO}_{2}$ samples. The $\mathrm{GO} /$ hollow $\mathrm{TiO}_{2}$ hierarchical structure could facilitate the separation of the EHPs and accordingly improve photocatalytic dynamics. Excessive rGO might block $\mathrm{TiO}_{2}$ active sites and restrict subsequent redox reactions with contaminant molecules. Furthermore, rGO could shield partially the light reaching the $\mathrm{TiO}_{2}$ surface, which lowered the photon utilization efficiency [29]. 


\section{3. $\mathrm{TiO}_{2} / \mathrm{Graphene-Based} \mathrm{Composite} \mathrm{with} \mathrm{Novel} \mathrm{Construction} \mathrm{or} \mathrm{Additives}$}

\subsection{Novel Construction}

\subsubsection{Hierarchically Ordered Macro-Mesoporous $\mathrm{TiO}_{2}-$ Graphene Films}

Jiang et al. synthesized hierarchically ordered macro-mesoporous $\mathrm{TiO}_{2}$ /graphene composite films via a confined self-assembly method (as shown in Figure 4), utilizing polystyrene spheres and pluronic P123 as a macrostructure scaffold and a mesostructured template, respectively. The integration of interconnected macropores in mesoporous films facilitates mass transport across the film, increases the contact area between reactant and the thin film, thus enormously improving their photodegradation activities toward organic dyes. Additionally, the incorporation of graphene into the titania films facilitates the acceptance and transfer of electrons, resulting in the effective suppression of the photogenerated charges' recombination. The electrochemical impedance spectra (EIS) exhibited a shorter semicircle with the component of graphene, which meant a charge-transfer resistance decrease both in the solid-state interface layer and on the surface [41].
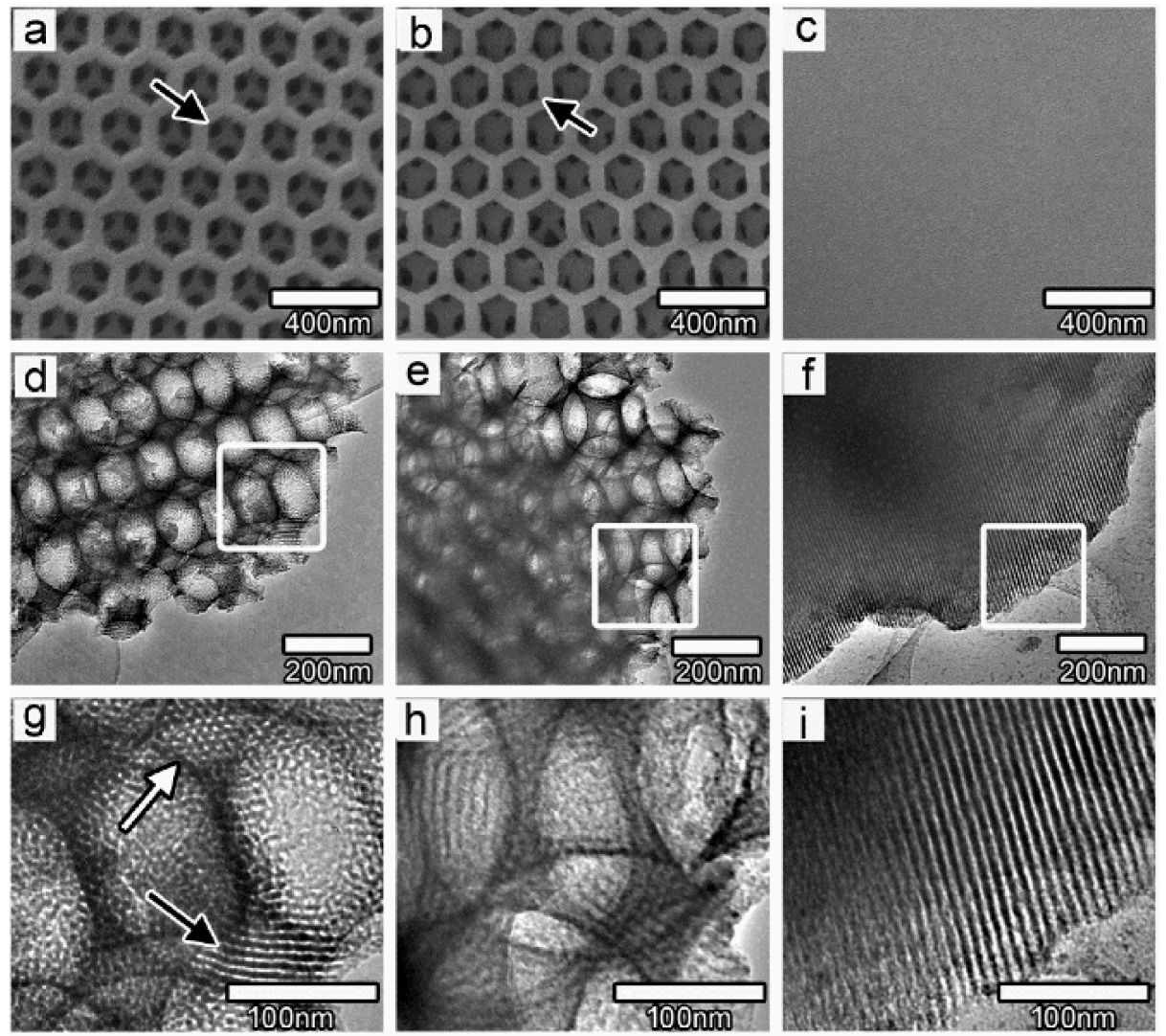

Figure 4. Representative SEM and TEM micrographs of macro-mesoporous titania films. (a,d,g) without grapheme; (b,e,h) with grapheme; (c,f,i) Representative SEM and TEM micrographs of pure mesoporous titania films (Reprint from [41] with permission from the American Chemical Society. Copyright 2011).

\subsection{2. $\mathrm{TiO}_{2} /$ Graphene Nanoflakes}

Kim et al. prepared self-assembled $\mathrm{TiO}_{2} / \mathrm{rGO}$ nanoflakes via continuous gas-phase synthesis. Compared with $\mathrm{P} 25-\mathrm{TiO}_{2} \mathrm{NP} /$ Large $\mathrm{rGO}$, the ultrafine $\mathrm{TiO}_{2}$ particles gain more access to the rGO nanoflakes. The more intimate contact between the $\mathrm{rGO}$ and $\mathrm{TiO}_{2}$ facilitates efficient electron migration, leading to better photocatalytic performance towards dyes degradation [42]. 


\subsection{3. $\mathrm{TiO}_{2} \mathrm{NP}$ Surrounded by Mono or Bilayer Graphene}

Fitri et al. prepared $\mathrm{TiO}_{2} /$ Graphene composites using a direct CVD process. Morphology measurements revealed that the surface of $\mathrm{TiO}_{2} \mathrm{NP}$ is partially surrounded by a mono or bilayer graphene. The formation of thin mono or double layer via CVD process at low temperature was attributed to the ability $\mathrm{TiO}_{2}$ surface working as a catalyst for aromatization. The $\mathrm{TiO}_{2} / \mathrm{Graphene}$ composite displayed increased photocatalytic activity and anti-fouling property compared to the bare $\mathrm{TiO}_{2}$. Wrapping a graphene layer can also work as a protection layer for the surface of $\mathrm{TiO}_{2}$ from adsorption by foulant. UV-vis absorption spectra of $\mathrm{TiO}_{2} /$ Graphene composites displayed a stronger absorption in the visible light region compared to bare $\mathrm{TiO}_{2}$, which can be explained by the $\pi$ electron of the carbon atom on the $\mathrm{TiO}_{2}$ surface form Ti-O-C structure, resulting in shifted VB edge and reduced band gap. The low intensity of $\mathrm{PL}$ with $\mathrm{TiO}_{2} /$ Graphene composites suggests low recombination rate of the photoinduced EHPs [30].

\subsection{With Functional Additives}

\subsubsection{Graphene Coating of $\mathrm{TiO}_{2}$ NP Loaded on Mesoporous Silica}

Yamashita et al. also developed a graphene coating wrapping $\mathrm{TiO}_{2} \mathrm{NPs}$ hybrid, except they introduced a mesoporous silica as support for the hybrid. $\mathrm{TiO}_{2} \mathrm{NPs}$ exhibited an anatase crystalline structure in the hybrid, while mesoporous silica kept its porous structure as well as the high surface area, after a high temperature carbonization process. Morphology measurement showed that the distribution of $\mathrm{TiO}_{2} \mathrm{NPs}$ anchored on silica was uniform and some ordered hexagonal arrays aligned in the 1D channel after high temperature carbonization. The selective graphene coating increased the adsorption capacity for 2-propanol near the $\mathrm{TiO}_{2}$ surface anchored on silica. The function of the support, mesoporous silica, is to provide a bonding site for $\mathrm{TiO}_{2} \mathrm{NPs}$, as well as exhibit no additional diffusion limitation for adsorbed organic molecules [43].

\subsubsection{With Floating Autoclaved Cellular Concrete}

The small size of $\mathrm{TiO}_{2}$ particles in powder form makes it difficult to recover used photocatalyst from treated water. In order to develop a photocatalyst with the property of easy recovery and even reuse, a floating autoclaved cellular concrete (ACC), which is an abundant, inert and low cost commercial material, was used to support $\mathrm{TiO}_{2} / \mathrm{Graphene}$ composite. The flotation capacity of the nanocomposite enables continuous and extensive contact with the UV radiation and even air oxygen, which are key factors for improving the efficiency of the photocatalytic process. The ACC $/ \mathrm{TiO}_{2}-\mathrm{GO}-8 \%$ nanocomposite exhibited relatively good photocatalytic performance in the degradation of three organic compounds and there was no significant release of active component from the ACC support when it was reused in successive cycles [44].

\subsubsection{Photocatalytic Reaction with Dye-Sensitization}

Dye sensitization can induce electron transfer and this process has been applied on a large scale to increase the photon-to-electron conversion efficiency of solar cells. Upon visible light irradiation, the photogenerated electrons from the excited dye are injected into the anode through semiconductor photocatalysts. Given that the similarity in electron transfer mechanism between dye-sensitized solar cells and photocatalytic reduction of GO, it is a feasible method to apply the dye sensitization mechanism for the reduction of GO. Lei et al. reported such reduction process of GO nanosheets induced by dye sensitization. As shown in Figure 5, the photogenerated electrons are firstly generated on the excited dye molecule and then transferred to the $\mathrm{GO}$ via the $\mathrm{CB}$ of $\mathrm{TiO}_{2}$, simultaneously reducing $\mathrm{GO}$ to $\mathrm{rGO}$. In order for the electron transfer to process successfully, strong coupling interface between the $\mathrm{TiO}_{2} \mathrm{NPs}$ and rGO is critical, which was evidenced by the difficult detachment of rGO nanosheets from the $\mathrm{TiO}_{2} \mathrm{NPs}$ by ultrasonic dispersion. During the reduction process, a $\mathrm{TiO}_{2} / \mathrm{rGO}$ composite was formed. It was shown that the $\mathrm{TiO}_{2} / \mathrm{rGO}$ composites displayed superior photocatalytic performance 
over pure $\mathrm{TiO}_{2}$ owing to the effective transfer and separation of photogenerated electrons by rGO nanosheets [45].
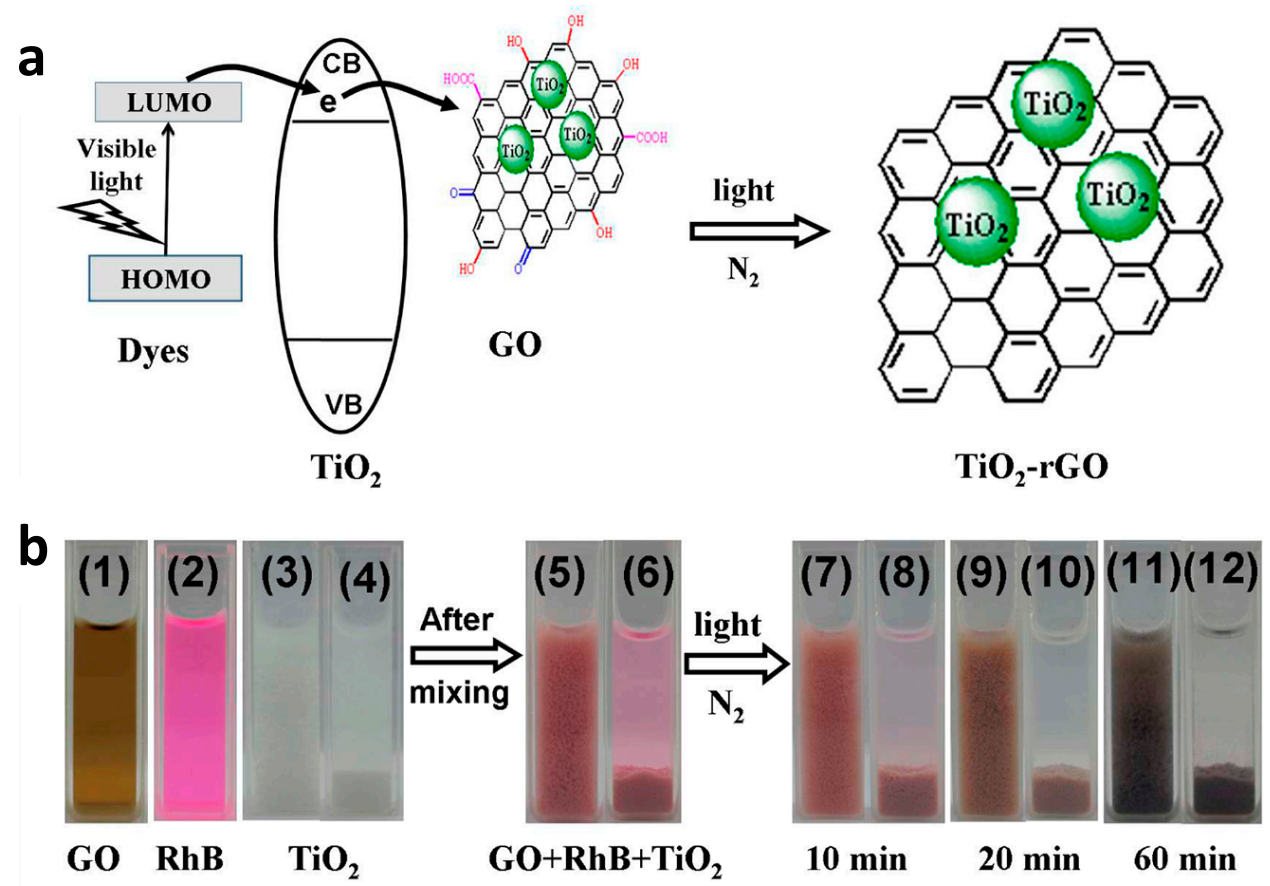

Figure 5. Schematic diagram illustrating the (a) dye-sensitization-induced visible-light reduction of GO nanosheets and the following formation of $\mathrm{TiO}_{2}-\mathrm{rGO}$ composite; (b) photographs of the (1) GO solution, (2) $\mathrm{RhB}$ solution, $(3,4) \mathrm{TiO}_{2}$ suspension, $(5,6) \mathrm{GO}+\mathrm{RhB}+\mathrm{TiO}_{2}$ mixing solution, (7-12) mixing solution after different irradiation time (Reprint from [45] with permission from the American Chemical Society. Copyright 2013).

\subsubsection{Photocatalytic Reaction with a Cu(II) Graft}

Transition metal ions, such as $\mathrm{Cu}(\mathrm{II})$, have been utilized to promote the multi-electron reduction of $\mathrm{O}_{2}$ and result in enhancing the photocatalytic efficiency of $\mathrm{TiO}_{2}$. Guo et al. reported anchoring $\mathrm{Cu}$ (II) on a $\mathrm{TiO}_{2} / \mathrm{rGO}$ mat could lead to an efficient photocatalytic degradation of phenol. Upon UV light irradiation, $\mathrm{rGO}$ transfers electrons from photoexcited $\mathrm{TiO}_{2}$ to the $\mathrm{Cu}(\mathrm{II})$ cluster efficiently, which subsequently leads to $\mathrm{O}_{2}$ multi-electron reduction. Due to the efficient consumption of electrons by $\mathrm{Cu}(\mathrm{II})$, more remaining $\mathrm{h}^{+}$from excited $\mathrm{TiO}_{2}$ take part in the subsequent photocatalytic degradation reaction. This process separates photogenerated EHPs and allows them to catalyze respective reactions at separated sites. As a result, $\mathrm{rGO}$ and $\mathrm{Cu}(\mathrm{II})$ brought in a pronounced improvement in the photocatalytic degradation of phenol. $\mathrm{TiO}_{2} / \mathrm{Cu}(\mathrm{II})$ and $\mathrm{TiO}_{2} / \mathrm{rGO}$ both displayed a decent photocatalytic activity, which can be attributed to efficient molecular oxygen activation by $\mathrm{Cu}$ (II) clusters and enhanced charge separation by rGO. The highest photocatalytic activity was achieved with $\mathrm{TiO}_{2} / \mathrm{rGO} / \mathrm{Gu}(\mathrm{II})$, indicating a synergistic effect from $\mathrm{Cu}(\mathrm{II})$ and $\mathrm{rGO}$ [46].

\subsubsection{Phenylamine \& Tourmaline Functionalization}

Photocatalytic degradation can work, in principle, on any kind of dye. So, selective degradation toward a specific dye remains a problem. To solve this problem, many researchers focused on the surface modification of $\mathrm{TiO}_{2}$ photocatalysts by using specific charged species or polarity molecules to control the surface charge structure. As a result, the dyes with opposite charge can be easily and preferentially adsorbed on the photocatalyst's surface, leading to desirable photocatalytic selectivity. In Yu et al.'s study, negative rGO nanosheets and positive phenylamine $\left(\mathrm{PhNH}_{2}\right)$ molecules were loaded at spatially separated loading sites of the $\mathrm{TiO}_{2}$ surface (as shown in Figure 6). Thus these locally charged sites can be favorable adsorption sites for dyes with opposite charges. The resultant $\mathrm{PhNH}_{2} / \mathrm{rGO}-\mathrm{TiO}_{2}$ 
photocatalyst achieved tunable photocatalytic selectivity and realized complete decomposition of dyes both with anionic and cationic charge. Under UV light irradiation, the photogenerated electrons will transfer efficiently to the $\mathrm{PhNH}_{2}$-modified rGO nanosheets to reduce oxygen. In the meantime, the photogenerated holes staying in the $\mathrm{VB}$ of $\mathrm{TiO}_{2}$ can transfer to the adsorbed anionic dyes to decompose them by oxidation. During the process of $\mathrm{H}_{2} \mathrm{O}$ or $-\mathrm{OH}$ oxidation by photogenerated holes, the produced hydroxyl radicals can easily diffuse onto the adsorbed cationic dyes on rGO surface, causing the decomposition of cationic dyes [47].

(a)

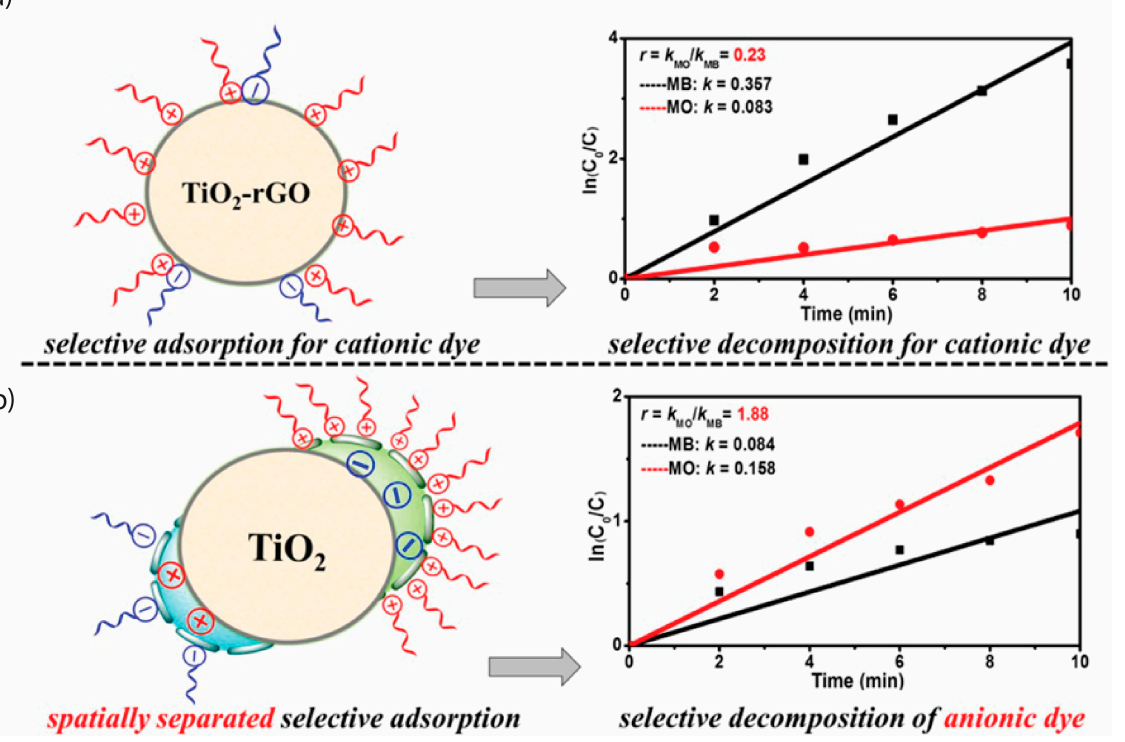

Figure 6. Schematic diagram illustrating (a) the adsorption behaviors of cationic and anionic dyes on $\mathrm{TiO}_{2}$ surface and corresponding decomposition rate of the MO-MB solutions; (b) the controllable selective adsorption of cationic and anionic dyes and corresponding decomposition rate (Reprint from [47] with permission from the American Chemical Society. Copyright 2016).

Tourmaline is a kind of borosilicate mineral with the electronic directional function. As a result of opposing charges existing at different sites of tourmaline particles, an electric field is present at the surface of tourmaline. Such an electric field favors the photogenerated opposing charges' transportation in the opposite directions. Wang et al. synthesized Graphene/Tourmaline/ $\mathrm{TiO}_{2}$ $\left(\mathrm{G} / \mathrm{T} / \mathrm{TiO}_{2}\right)$ composites via a hydrothermal method. This ternary composite displayed an excellent photocatalytic activity toward degradation of 2-propanol, which was superior to that of the binary systems $\left(\mathrm{G} / \mathrm{TiO}_{2}, \mathrm{~T} / \mathrm{TiO}_{2}\right)$ or bare $\mathrm{TiO}_{2}$. The improved photocatalytic activity was ascribed to the synergetic effect of tourmaline and graphene. Once electrons are photogenerated in $\mathrm{TiO}_{2}$, graphene can effectively transfer both electrons and holes but in opposite directions, owing to the electronic field of tourmaline. As a result, the recombination of EHPs was greatly restricted. This is evidenced by the PL intensity decrease and the slight blue shift of the PL peak for the $\mathrm{G} / \mathrm{T} / \mathrm{TiO}_{2}$ compared with those for $\mathrm{TiO}_{2}$ [48].

\subsubsection{Antibacterial Polyacylic Coating \& Biopolymer}

Dispersion of $\mathrm{TiO}_{2}$ NPs in the matrix of polymers is of importance in respect of practical application. Acrylic polymers can be used as durable outdoor coatings because of their good chemical resistance. The incorporation of $\mathrm{TiO}_{2}$ with polymers can lead to self-cleaning acrylic coatings. A $\mathrm{TiO}_{2} / \mathrm{GO}$ nanocomposite was added to commercial grade polyacrylic latex to obtain a coating with self-cleaning ability and the property of excellent photodegradation. The polyacrylic coatings modified with $\mathrm{TiO}_{2} / \mathrm{GO}$ nanocomposites were used to decompose $\mathrm{MB}$ and displayed an excellent activity. The optimized weight ratio for $\mathrm{TiO}_{2} / \mathrm{GO}$ in the composite was $3 \% \mathrm{wt}$, in which the ratio of 
$\mathrm{TiO}_{2}$ to GO was 100:20. In addition, the self-cleaning ability was proved by a water contact angle of $12^{\circ}$ after $24 \mathrm{~h}$ LED light irradiation, coating stability in water was verified as well [49].

The incorporation of $\mathrm{TiO}_{2} \mathrm{NPs}$ with biocompatible polysaccharides matrix is of interest due to its high mechanical strength, perfect suppleness and better photocatalytic performance. Khan et al. prepared a $\mathrm{TiO}_{2} / \mathrm{GO}$ incorporated alginate (Alg)/carboxymethyl cellulose (CMC) nanocomposite via a dissipative convective technique followed by a freeze drying process. Morphological analysis revealed that highly ordered capillaries and pores were present in the composite. Several benefits were realized with such structure including self-organization of microstructure, anti-agglomeration of NPs and uniform dispersion of GO within the nanocomposite. Furthermore, the as-prepared $\mathrm{Alg} / \mathrm{CMC} / \mathrm{GO} / \mathrm{TiO}_{2}$ nanocomposite displayed better photodegradation toward congo red dye than the $\mathrm{Alg} / \mathrm{CMC}, \mathrm{Alg} / \mathrm{CMC} / \mathrm{TiO}_{2}$ and $\mathrm{TiO}_{2}$ alone [50].

\subsection{7. $\mathrm{TiO}_{2} /$ Graphene Composite with Surfactant \& Surface Fluorination}

The functionalization of graphene-based material with surfactant is multiple. For example, there were reports about graphene sheets' functionalization by the surfactant molecules [51-53]. The work by Martín-García et al. especially pointed out that the utilization of a zwitterionic surfactant $\mathrm{N}$-dodecyl- $\mathrm{N}, \mathrm{N}$-dimethyl-3-ammonio-1-propanesulfonate (DDPS) was able to improve the reduction efficiency in the reduction process of GO to rGO. Besides, the introduction of DDPS increased the

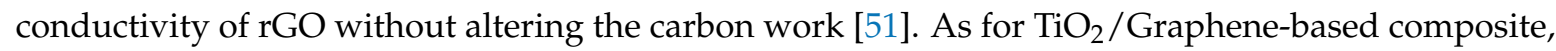
the modification with surfactant is an effective method to control their morphologies and structures. Xin et al. synthesized a $\mathrm{TiO}_{2} / \mathrm{GO}$ nanocomposite with a flower-shaped structure with the assistance of sodium dodecyl benzene sulfonate (SDBS) as the surfactant [11]. In Wu et al.'s work, cetyl trimethyl ammonium bromide (CTAB) was used as a cationic surfactant to synthesize $\mathrm{TiO}_{2} / \mathrm{rGO}$ nanocomposite with a novel morphology (Figure 7). Besides, SDBS and Triton X-100 were used as surfactant to regulate the phase structure and morphology of $\mathrm{TiO}_{2} / \mathrm{rGO}$ composites as well, leading to $\mathrm{TiO}_{2} \mathrm{NPs}$ and distributed NWs respectively. With array-like $\mathrm{TiO}_{2}$ nanowires grown on the surface of rGO, $\mathrm{TiO}_{2} /$ rGO-CTAB displayed an excellent photocatalytic efficiency to remove almost all of the MB molecules. Surfactant-assisted hydrothermal method was proved to be an effective approach to improve the structure, morphology and photocatalytic performance of $\mathrm{TiO}_{2} / \mathrm{rGO}$ composites [54].

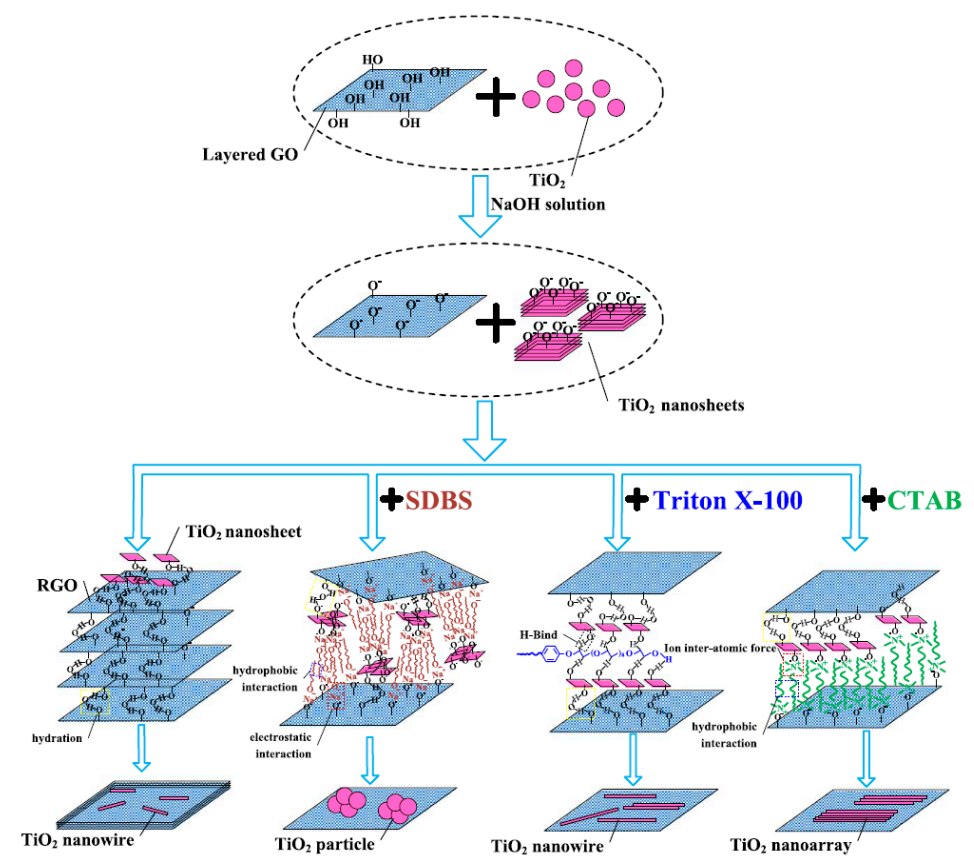

Figure 7. Illustration of the preparation processes and growth mechanism of $\mathrm{TiO}_{2}$-based nanocomposites (Reprint from [54] with permission from Elsevier. Copyright 2017). 
Surface fluorination of $\mathrm{TiO}_{2}$ is another way of surface modification, which can be completed simply by a ligand exchange between surface hydroxyl groups on $\mathrm{TiO}_{2}$ and fluoride ions $\left(\mathrm{F}^{-}\right)$. Surface fluorinated $\mathrm{TiO}_{2} / \mathrm{rGO}$ (FTG) was synthesized using $\mathrm{HF}$ as the source for providing $\mathrm{F}^{-}$. The $\mathrm{F}^{-}$ ions anchored on the surface of $\mathrm{TiO}_{2} \mathrm{NPs}$ and thus enhanced the crystallization of the $\mathrm{TiO}_{2}$ anatase phase. The reason for enhanced photocatalytic activity was partly attributed to $\mathrm{F}^{-}$induced favorable crystallization of anatase $\mathrm{TiO}_{2}$ and the accelerated photocatalytic degradation mediated by $\bullet \mathrm{OH}$ radical. The total decomposition ratio of $17 \beta$-estrodiol over FTG was high-up to $99.8 \%$ after a $2 \mathrm{~h}$ illumination-while the corresponding value of $17 \alpha$-ethynyl-estradiol was $99.7 \%$ after a $3 \mathrm{~h}$ illumination [55].

\subsubsection{With Heteroatom Doping}

In addition to surface modification, the functionalization of graphene by chemical doping has been applied in photocatalysis as well. Among various heteroatom dopants, the nitrogen doping is an effective way to significantly improve the photocatalytic performance. Three typical N-bonding configurations including graphitic $\mathrm{N}$, pyridinic $\mathrm{N}$ and pyrrolic $\mathrm{N}$ can be observed. The relationship between $\mathrm{N}$-bonding configuration and the photocatalytic performance of $\mathrm{N}$-doped graphene-based composite was studied by $\mathrm{Yu}$ et al. The $\mathrm{N}-\mathrm{rGO} / \mathrm{TiO}_{2}\left(\mathrm{~N}_{2} \mathrm{H}_{4}\right)$, with ca. $63 \%$ pyrrolic $\mathrm{N}$ and ca. $37 \%$ graphitic N-bonding, displayed a 3.63 and 2.64 times higher photocatalytic activity than that of $\mathrm{TiO}_{2}$ and $\mathrm{rGO} / \mathrm{TiO}_{2}$ respectively. The graphene with graphitic-N configuration functions as an effective electron mediator while the one with pyrrolic- $\mathrm{N}$ performs as the oxygen reduction active site [56].

In S-doped $\mathrm{TiO}_{2}$, the mixing of $\mathrm{S}_{3 p}$ state with $\mathrm{O}_{2 p}$ state can cause a defect state in the band gap. S- $\mathrm{TiO}_{2}-3 \mathrm{D}$ graphene aerogel (3DGA) nanocomposites are prepared via a hydrothermal method followed by a freeze-drying treatment. The as-synthesized $\mathrm{S}_{-} \mathrm{TiO}_{2}-3 \mathrm{DGA}$ catalyst exhibited fairly high photocatalytic activity under the irradiation of UV and visible light. The function of S-doping on the photocatalytic performance was summarized as follows. Firstly, the redshift in the bandgap edge of the $\mathrm{S}-\mathrm{TiO}_{2}$ can decrease the value of band gap, thus extending the light absorption range into the visible region. Secondly, with $S$ dopant, the electron-deficient oxygen could serve as an electron trap to capture electrons, thus reducing the recombination of EHPs [57].

The $\mathrm{N}, \mathrm{V}-\mathrm{TiO}_{2}-\mathrm{rGO}$ was prepared through a facile hydrothermal process, which exhibited much higher visible light photocatalytic activity than bare $\mathrm{TiO}_{2}, \mathrm{~N}-\mathrm{TiO}_{2}$ and $\mathrm{N}, \mathrm{V}-\mathrm{TiO}_{2}$. The nanocomposites had good stability and their recovery was achieved as well. A $\mathrm{N}_{2 p}$ state forms due to $\mathrm{N}$ doping and overlaps with $\mathrm{O}_{2 p}$ states, thus lifting the VB top, that is, reducing the band gap. The dopant $\mathrm{V}$ would exist in the form of $\mathrm{V}_{2} \mathrm{O}_{5}$, which is another semiconductor facilitating further extended light absorption [58].

\section{Mechanism on Enhanced Photocatalytic Activity by Graphene-Based Material}

This paper reviews plenty of research on enhanced photocatalytic activity brought on by incorporation of graphene. With a detailed study on graphene's role from various aspects, there are some common conclusions on one can draw upon. Firstly, as evidenced in reference [22], the $\mathrm{TiO}_{2} / \mathrm{GO}$ hybrid has a higher BET surface area $\left(190 \mathrm{~m}^{2} / \mathrm{g}\right)$ than both free $\mathrm{TiO}_{2}$ grown in solution $\left(121 \mathrm{~m}^{2} / \mathrm{g}\right)$ and P25 $\left(58 \mathrm{~m}^{2} / \mathrm{g}\right)$. In reference [19], a similar enhancement in specific surface area was reported in the TGH due to $\mathrm{TiO}_{2}$ NPs decoration on graphene nanosheets, so as to partially prevent the aggregation of the graphene sheets. Both the above two cases reported a higher surface area accessible to pollutant molecules in the composite containing graphene, so the amount of physisorption of pollutant molecules is obviously increased. Secondly, the $\pi-\pi$ electron coupling between the aromatic region on graphene's surface and aromatic molecules strengthens the interaction with each other [19], further increasing the adsorption of molecules to be decomposed. Thirdly, the excellent electronic conductivity of graphene makes it an ideal electron transfer highway through the interconnected composite, which fastens the separation of photogenerated charge carriers [38] and as a result, inhibits effectively the recombination of EHPs [24,25,30,41]. In Reference [38], Cyclic voltammograms (CV) and EIS measurements were used 
to disclose the transfer and separation efficiency of photoinduced EHPs. The hybrid with graphene sheets exhibited large current density, indicating a much increased rate of electron transfer attributed to the introduction of the graphene. $\mathrm{TiO}_{2} /$ Graphene exhibited a smaller arc radium in Nyquist diagram than pure $\mathrm{TiO}_{2}$, indicating a smaller charge transfer resistance, that is, the fast interfacial transfer and effective separation of photogenerated EHPs at the hybrid interfaces. The PL emission spectra in [24] exhibited a decrease in intensity of PL peak with $\mathrm{TiO}_{2} / \mathrm{rGO}$ composites, which attribute to inhibition of the EHPs recombination, thus extending the $\mathrm{h}^{+}$existence time. Similarly, in reference [25] the PL intensity was quenched with $\mathrm{TiO}_{2} / \mathrm{rGO}$ composite as effective interaction of photo-induced EHPs with the close interfacial contact of rGO sheet, acting as electron acceptor, reduces their radiative recombination. Fourthly, the way of graphene supporting $\mathrm{TiO}_{2}$, regardless of the form of $\mathrm{NPs}$ or other structures, prevents effectively the aggregation of $\mathrm{TiO}_{2}$, thus expanding the exposed $\mathrm{TiO}_{2}$ surface to a maximum. As a result, the light absorption intensity is absorbed. Finally, because graphene itself can absorb visible light and in the $\mathrm{TiO}_{2} /$ Graphene composite, a Ti-O-C chemical bond is formed [30,39], or electronic transitions occur between carbon and $\mathrm{TiO}_{2}$ phases [59], the light absorption edge is red-shifted from UV to the visible light region, thus narrowing the band gap [9,32,38]. In reference [32] $\mathrm{TiO}_{2} / \mathrm{GO}$ catalyst's excellent electronic properties result in excellent photocatalytic behavior under visible light. It was always in the case of $\mathrm{TiO}_{2} / \mathrm{GO}$ that a higher initial photo-oxidation rate was achieved compared to that of the commercial $\mathrm{TiO}_{2} \mathrm{P} 25$ material. In reference [38], $\mathrm{TiO}_{2} / \mathrm{Graphene}$ exhibited a higher $\mathrm{MB}$ degradation rate than pure $\mathrm{TiO}_{2}$, due to $\mathrm{TiO}_{2}$ interacted with graphene surface hydroxyl groups, resulting in forming Ti-O-C bonds through hydrothermal reaction.

This knowledge greatly enriches our understanding of graphene's unique function in improving semiconductor photocatalysis, such as $\mathrm{TiO}_{2}$. But it does not exclude the possibility that there still exist some disputes regarding graphene's specific property. For example, some scientists believe that a large percentage of enhanced photocatalytic activity should be ascribed to the PTE of graphene instead of other factors. Interesting topics like this will spur more intensive study into the field of graphene-based photocatalysis.

\section{Conclusions}

The recent progress in the incorporation of graphene with $\mathrm{TiO}_{2}$ is summarized. As the morphology of $\mathrm{TiO}_{2}$ component varies from 0D NP through 1D NT/NW, to 2D nanosheet, the contact between $\mathrm{TiO}_{2}$ and graphene gets more intimate and the distribution becomes more uniform. Both factors facilitate better photocatalytic performance. The graphene's roles are mainly as follows: higher surface area, more efficient charge transfer, inhibited EHPs' recombination and extended light absorption range. With the assistance of some functional surfactant, the photodegradation performance can be further improved according to more specific requirements such as the photodegradation selectivity.

It is worth noticing that the samples we reviewed are mostly suspended functional composites. Recently, another branch of substrate-supported functional composites has attracted lots of attentions. As for such supported system, Raman spectroscopy by itself, or through the combination with atomic force microscopy (AFM) or Rayleigh spectroscopy, emerges as a powerful characterization tool and many insightful conclusions have been obtained [60-68]. Among the above works, several studies involved investigate especially the substrate-supported graphene or few-layer graphene (FLG) systems $[60,61]$. Caridad et al. studied the inhomogeneities in the charge density of unintentionally doped graphene supported on $\mathrm{SiO}_{2}$ via Raman spectra; they attributed the doping of graphene to its interaction with substrate other than particle contamination [60]. Besides, the evolution of Raman features is similar to the behavior of suspended graphene [69,70], of which the main conclusion is that the absence of the interaction with a substrate essentially results in an undoped pristine graphene. By utilizing Raman spectroscopy and AFM, Caridad et al. also successfully detect and characterize graphene and FLG in an automated manner. The algorithm they designed provided a basic but robust characterization tool of graphene and FLG in spite of any type of substrate [61]. It is obvious graphene-substrate interaction is one important factor influencing the doping of graphene, or even the 
electronic structure of the graphene-based system. By analogy, it is a reasonable expectation that within a supported $\mathrm{TiO}_{2} /$ Graphene composite system, the interaction between substrate and functional composites will play a key role in subsequently determining the photocatalytic and electrochemical behavior. The researches in this promising field will provide more inspirational insights into the $\mathrm{TiO}_{2} /$ Graphene system.

Acknowledgments: We acknowledge the Danish Research Council, AUFF NOVA-project from Aarhus Universitets Forskningsfond and EU H2020 RISE 2016-MNR4SCell project.

Author Contributions: Peipei Huo made her contribution in literature search, design and writing of the whole manuscript. Bo Liu and Mingdong Dong made their contributions in design and editing of the manuscript. Peng Zhao made his contribution in literature search and writing of Section 2 mainly. Yin Wang made his contribution in writing of Section 3 mainly.

Conflicts of Interest: The authors declare no conflict of interest. The founding sponsors had no role in the design of the study; in the collection, analyses, or interpretation of data; in the writing of the manuscript and in the decision to publish the results.

\section{References}

1. Ohko, Y.; Luchi, K.; Niwa, C.; Tatsuma, T.; Nakashima, T.; Iguchi, T.; Kubota, Y.; Fujishima, A. 17 $\beta$-estradiol degradation by $\mathrm{TiO}_{2}$ photocatalysis as a means of reducing estrogenic activity. Environ. Sci. Technol. 2002, 36, 4175-4181. [CrossRef] [PubMed]

2. Schneider, J.; Matsuoka, M.; Takeuchi, M.; Zhang, J.L.; Horiuchi, Y.; Anpo, M.; Bahnemann, D.W. Understanding $\mathrm{TiO}_{2}$ photocatalysis: Mechanisms and materials. Chem. Rev. 2014, 114, 9919-9986. [CrossRef] [PubMed]

3. Lee, J.; Kim, J.; Choi, W. $\mathrm{TiO}_{2}$ photocatalytis for the redox conversion of aquatic pollutants. Aquat. Redox Chem. 2011, 10, 199-222. [CrossRef]

4. Diesen, V.; Jonsson, M. Formation of $\mathrm{H}_{2} \mathrm{O}_{2}$ in $\mathrm{TiO}_{2}$ photocatalysis of oxygenated and deoxygenated aqueous system: A probe for photocatalytically produced hydroxyl radicals. J. Phys. Chem. C 2014, 118, 10083-10087. [CrossRef]

5. Kuznetsov, V.N.; Serpone, N. On the origin of the spectral bands in the visible absorption spectra of visible-light-active $\mathrm{TiO}_{2}$ specimens analysis and assignments. J. Phys. Chem. C 2009, 113, 15110-15123. [CrossRef]

6. Choi, J.; Park, H.; Hoffmann, M.R. Effects of single metal-ion doping on the visible-light photoreactivity of $\mathrm{TiO}_{2}$. J. Phys. Chem. C 2010, 114, 783-792. [CrossRef]

7. Pan, H.; Zhang, Y.W.; Shenoy, V.B.; Gao, H.J. Effects of H-, N-, and (H, N)-doping on the photocatalytic activity of $\mathrm{TiO}_{2}$. J. Phys. Chem. C 2011, 115, 12224-12231. [CrossRef]

8. Valero, J.M.; Obregón, S.; Colón, G. Active site considerations on the photocatalytic $\mathrm{H}_{2}$ evolution performance of $\mathrm{Cu}$-doped $\mathrm{TiO}_{2}$ obtained by different doping methods. ACS Catal. 2014, 4, 3320-3329. [CrossRef]

9. Štengl, V.; Popelková, D.; Vlácil, $\mathrm{P}$. $\mathrm{TiO}_{2}$-graphene nanocomposite as high performance photocatalysts. J. Phys. Chem. C 2011, 115, 25209-25218. [CrossRef]

10. Zhu, P.N.; Nair, A.S.; Peng, S.J.; Yang, S.Y.; Ramakrishna, S. Facile fabrication of $\mathrm{TiO}_{2}$-graphene composite with ehhanced photovoltaic and photocatalytic properties by electrospinning. ACS Appl. Mater. Interfaces 2012, 4, 581-585. [CrossRef] [PubMed]

11. Xin, X.; Zhou, X.F.; Wu, J.H.; Yao, X.Y.; Liu, Z.P. Scalable synthesis of $\mathrm{TiO}_{2}$ /graphene nanostructured composite with high-rate performance for lithium ion batteries. ACS Nano 2012, 6, 11035-11043. [CrossRef] [PubMed]

12. Cheng, G.; Akhtar, M.S.; Yang, O.B.; Stadler, F.J. Novel preparation of anatase $\mathrm{TiO}_{2} @$ reduced graphene oxide hybrids for high-performance dye-sensitized solar cells. ACS Appl. Mater. Interfaces 2013, 5, 6635-6642. [CrossRef] [PubMed]

13. Tang, L.A.L.; Wang, J.Z.; Lim, T.K.; Bi, X.Z.; Lee, W.C.; Lin, Q.S.; Chang, Y.T.; Lim, C.T.; Loh, K.P. High-performance graphene-titania platform for detection of phosphopeptides in cancer cells. Anal. Chem. 2012, 84, 6693-6700. [CrossRef] [PubMed]

14. Shiraishi, Y.; Shiota, S.; Hirakawa, H.; Tanaka, S.; Ichikawa, S.; Hirai, T. Titanium dioxide/reduced graphene oxide hybrid photocatalysts for efficient and selective partial oxidation of cyclohexane. ACS Catal. 2017, 7, 293-300. [CrossRef] 
15. Li, W.; Wang, F.; Feng, S.S.; Wang, J.X.; Sun, Z.K.; Li, B.; Li, Y.H.; Yang, J.P.; Elzatahry, A.A.; Xia, Y.Y.; et al. Sol-gel design strategy for ultradispersed $\mathrm{TiO}_{2}$ nanoparticles on graphene for high-performance lithium ion batteries. J. Am. Chem. Soc. 2013, 135, 18300-18303. [CrossRef] [PubMed]

16. Bianco, A.; Cheng, H.M.; Enoki, T.; Gogotsi, Y.; Hurt, R.H.; Koratkar, N.; Kyotani, T.; Monthioux, M.; Park, C.R.; Tascon, J.M.D.; et al. All in the graphene family-A recommended nomenclature for two-dimensional carbon materials. Carbon 2013, 65, 1-6. [CrossRef]

17. Zhang, Y.H.; Tang, Z.R.; Fu, X.Z.; Xu, Y.J. TiO ${ }_{2}$-graphene nanocomposites for gas-phase photocatalytic degradation of volatile aromatic pollutant: $\mathrm{Is} \mathrm{TiO}_{2}$-graphene truly different from other $\mathrm{TiO}_{2}$-carbon composite materials? ACS Nano 2010, 4, 7303-7314. [CrossRef] [PubMed]

18. Moon, G.H.; Kim, D.H.; Kim, H.I.; Bokare, A.D.; Choi, W. Platinum-like behavior of reduced graphene oxide as a cocatalyst on $\mathrm{TiO}_{2}$ for the efficient photocatalytic oxidation of arsenite. Environ. Sci. Technol. Lett. 2014, 1,185-190. [CrossRef]

19. Zhang, Z.Y.; Xiao, F.; Guo, Y.L.; Wang, S.; Liu, Y.Q. One-pot self-assembled three-dimensional TiO ${ }_{2}$-graphene hydrogel with improved adsorption capacities and photocatalytic and electrochemical activities. ACS Appl. Mater. Interfaces 2013, 5, 2227-2233. [CrossRef] [PubMed]

20. Gan, Z.X.; Wu, X.L.; Meng, M.; Zhu, X.B.; Yang, L.; Chu, P.K. Photothermal contribution to enhanced photocatalytic performance of graphene-based nanocomposites. ACS Nano 2014, 8, 9304-9310. [CrossRef] [PubMed]

21. Chen, C.; Cai, W.M.; Long, M.C.; Zhou, B.X.; Wu, Y.H.; Wu, D.Y.; Feng, Y.J. Synthesis of visible-light responsive graphene oxide/ $\mathrm{TiO}_{2}$ composites with $\mathrm{p} / \mathrm{n}$ heterojunction. ACS Nano 2010, 4, 6425-6432. [CrossRef] [PubMed]

22. Liang, Y.Y.; Wang, H.L.; Casalongue, H.S.; Chen, Z.; Dai, H.J. $\mathrm{TiO}_{2}$ nanocrystals grown on graphene as advanced photocatalytic hybrid materials. Nano Res. 2010, 3, 701-705. [CrossRef]

23. Zhu, C.Y.; Liu, G.G.; Han, K.; Ye, H.Q.; Wei, S.C.; Zhou, Y.H. One-step facile synthesis of graphene oxide $/ \mathrm{TiO}_{2}$ composite as efficient photocatalytic membrane for water treatment: Crossflow filtration operation and membrane fouling analysis. Chem. Eng. Process. Process Intensif. 2017, 120, 20-26. [CrossRef]

24. Pu, S.Y.; Zhu, R.X.; Ma, H.; Deng, D.L.; Pei, X.J.; Qi, F.; Chu, W. Facile in-situ design strategy to disperse $\mathrm{TiO}_{2}$ nanoparticles on graphene for the enhanced photocatalytic degradation of rhodamine 6G. Appl. Catal. B Environ. 2017, 218, 208-219. [CrossRef]

25. Mukhopadhyay, S.; Maiti, D.; Saha, A.; Devi, P.S. Shape transition of $\mathrm{TiO}_{2}$ nanocube to nanospindle embedded on reduced graphene oxide with enhanced photocatalytic activity. Cryst. Growth Des. 2016, 16, 6922-6932. [CrossRef]

26. Pan, X.; Zhao, Y.; Liu, S.; Korzeniewski, C.L.; Wang, S.; Fan, Z.Y. Comparing graphene-TiO ${ }_{2}$ nanowire and graphene- $\mathrm{TiO}_{2}$ nanoparticle composite photocatalysts. ACS Appl. Mater. Interfaces 2012, 4, 3944-3950. [CrossRef] [PubMed]

27. Sun, J.; Zhang, H.; Guo, L.H.; Zhao, L. Two-dimensional interface engineering of a titania-graphene nanosheet composite for improved photocatalytic activity. ACS Appl. Mater. Interfaces 2013, 5, 13035-13041. [CrossRef] [PubMed]

28. Gu, L.; Wang, J.; Cheng, H.; Zhao, Y.; Liu, L.; Han, X. One-step preparation of graphene-supported anatase $\mathrm{TiO}_{2}$ with exposed $\{001\}$ facets and mechanism of enhanced photocatalytic properties. ACS Appl. Mater. Interfaces 2013, 5, 3085-3093. [CrossRef] [PubMed]

29. Zhang, L.; Zhang, J.; Jiu, H.; Ni, C.; Zhang, X.; Xu, M. Graphene-based hollow $\mathrm{TiO}_{2}$ composites with enhanced photocatalytic activity for removal of pollutants. J. Alloys Compd. 2015, 86, 82-89. [CrossRef]

30. Fitri, M.A.; Ota, M.; Hirota, Y.; Uchida, Y.; Hara, K.; Ino, D.; Nishiyama, N. Fabrication of TiO ${ }_{2}$-graphene photocatalyst by direct chemical vapor deposition and its anti-fouling property. Mater. Chem. Phys. 2017, 198, 42-48. [CrossRef]

31. Fotiou, T.; Triantis, T.M.; Kaloudis, T.; Pastrana-Martínez, L.M.; Likodimos, V.; Falaras, P.; Silva, A.M.T.; Hiskia, A. Photocatalytic degradation of microcystin-LR and off-odor compounds in water under UV-A and solar light with a nanostructured photocatalyst based on reduced graphene oxide- $\mathrm{TiO}_{2}$ composite: Identification of intermediate products. Ind. Eng. Chem. Res. 2013, 52, 13991-14000. [CrossRef]

32. Cruz, M.; Gomez, C.; Duran-Valle, C.J.; Pastrana-Martínez, L.M.; Faria, J.L.; Silva, A.M.T.; Faraldos, M.; Bahamonde, A. Bare $\mathrm{TiO}_{2}$ and graphene oxide $\mathrm{TiO}_{2}$ photocatalysts on the degradation of selected pesticides and influence of the water matrix. Appl. Surf. Sci. 2017, 416, 1013-1021. [CrossRef] 
33. Gan, Z.X.; Wu, X.L.; Zhou, G.X.; Shen, J.C.; Chu, P.K. Is there real upconversion photoluminescence from graphene quantum dots? Adv. Opt. Mater. 2013, 1, 554-558. [CrossRef]

34. Jiang, B.J.; Tian, C.G.; Pan, Q.J.; Jiang, Z.; Wang, J.Q.; Yan, W.; Fu, H.G. Enhanced photocatalytic activity and electron transfer mechanisms of graphene $/ \mathrm{TiO}_{2}$ with exposed $\{001\}$ facets. J. Phys. Chem. C 2011, 115, 23718-23725. [CrossRef]

35. Shah, M.S.A.S.; Park, A.R.; Zhang, K.; Park, J.H.; Yoo, P.J. Green synthesis of biphasic $\mathrm{TiO}_{2}$-reduced graphene oxide nanocomposites with highly enhanced photocatalytic activity. ACS Appl. Mater. Interfaces 2012, 4, 3893-3901. [CrossRef] [PubMed]

36. Li, H.N.; Zhu, M.Y.; Chen, W.; Xu, L.; Wang, K. Non-light-driven reduced graphene oxide anchored $\mathrm{TiO}_{2}$ nanocatalysts with enhanced catalytic oxidation performance. J. Colloid Interface Sci. 2017, 507, 35-41. [CrossRef] [PubMed]

37. Perera, S.D.; Mariano, R.G.; Vu, K.; Nour, N.; Seitz, O.; Chabal, Y.; Balkus, K.J., Jr. Hydrothermal synthesis of graphene- $\mathrm{TiO}_{2}$ nanotube composites with enhanced photocatalytic activity. ACS Catal. 2012, 2, 949-956. [CrossRef]

38. Liu, C.; Zhang, L.; Liu, R.; Gao, Z.; Yang, X.; Tu, Z.; Yang, F.; Ye, Z.; Cui, L.; Xu, C.; et al. Hydrothermal synthesis of $\mathrm{N}$-doped $\mathrm{TiO}_{2}$ nanowires and $\mathrm{N}$-doped graphene heterostructures with enhanced photocatalytic properties. J. Alloys Compd. 2016, 656, 24-32. [CrossRef]

39. Wang, W.S.; Wang, D.H.; Qu, W.G.; Lu, L.Q.; Xu, A.W. Large ultrathin anatase $\mathrm{TiO}_{2}$ nanosheets with exposed \{001\} facets on graphene for enhanced visible light photocatalytic activity. J. Phys. Chem. C 2012, 116, 19893-19901. [CrossRef]

40. Wang, X.Y.; Wang, J.; Dong, X.L.; Zhang, F.; Ma, L.; Fei, X.; Zhang, X.; Ma, H. Synthesis and catalytic performance of hierarchical $\mathrm{TiO}_{2}$ hollow sphere/reduced graphene oxide hybrid nanostructures. J. Alloys Compd. 2016, 656, 181-188. [CrossRef]

41. Du, J.; Lai, X.Y.; Yang, N.L.; Zhai, J.; Kisailus, D.; Su, F.; Wang, D.; Jiang, L. Hierarchically ordered macro-mesoporous $\mathrm{TiO}_{2}$-graphene composite films: Improved mass transfer, reduced charge recombination, and their enhanced photocatalytic activities. ACS Nano 2011, 5, 590-596. [CrossRef] [PubMed]

42. Byeon, J.H.; Kim, Y.W. Gas-phase self-assembly of highly ordered titania@graphene nanoflakes for enhancement in photocatalytic activity. ACS Appl. Mater. Interfaces 2013, 5, 3959-3966. [CrossRef] [PubMed]

43. Kamegawa, T.; Yamahana, D.; Yamashita, H. Graphene coating of $\mathrm{TiO}_{2}$ nanoparticles loaded on mesoporous silica for enhancement of photocatalytic activity. J. Phys. Chem. C 2010, 114, 15049-15053. [CrossRef]

44. Suave, J.; Amorim, S.M.; Moreira, R.F.P.M. $\mathrm{TiO}_{2}$-graphene nanocomposite supported on floating autoclaved cellular concrete for photocatalytic removal of organic compounds. J. Environ. Chem. Eng. 2017, 5, 3215-3223. [CrossRef]

45. Wang, P.; Wang, J.; Ming, T.S.; Wang, X.; Yu, H.G.; Yu, J.G.; Wang, Y.G.; Lei, M. Dye-sensitization-induced visible-light reduction of graphene oxide for the enhanced $\mathrm{TiO}_{2}$ photocatalytic performance. ACS Appl. Mater. Interfaces 2013, 5, 2924-2929. [CrossRef] [PubMed]

46. Zhang, H.; Guo, L.H.; Wang, D.B.; Zhao, L.X.; Wan, B. Light-induced efficient molecular oxygen activation on a $\mathrm{Cu}(\mathrm{II})$-grafted $\mathrm{TiO}_{2}$ /graphene photocatalyst for phenol degradation. ACS Appl. Mater. Interfaces 2015, 7, 1816-1823. [CrossRef] [PubMed]

47. Yu, H.G.; Xiao, P.; Tian, J.; Wang, F.Z.; Yu, J.G. Phenylamine-functionalized $\mathrm{rGO} / \mathrm{TiO}_{2}$ photocatalysts: Spatially separated adsorption sites and tunable photocatalytic selectivity. ACS Appl. Mater. Interfaces 2016, 8, 29470-29477. [CrossRef] [PubMed]

48. Yin, L.L.; Zhao, M.; Hu, L.H.; Ye, J.H.; Wang, D.F. Synthesis of graphene/tourmaline $/ \mathrm{TiO}_{2}$ composites with enhanced activity for photocatalytic degradation of 2-propanol. Chin. J. Catal. 2017, 38, 1307-1314. [CrossRef]

49. Nosrati, R.; Olad, A.; Shakoori, S. Preparation of an antibacterial, hydrophilic and photocatalytically active polyacrylic coating using $\mathrm{TiO}_{2}$ nanoparticles sensitized by graphene oxide. Mater. Sci. Eng. C 2017, 80, 642-651. [CrossRef] [PubMed]

50. Thomas, M.; Natarajan, T.S.; Sheikh, M.U.D.; Bano, M.; Khan, F. Self-organized graphene oxide and $\mathrm{TiO}_{2}$ nanoparticles incorporated alginate/carboxymethyl cellulose nanocomposites with efficient photocatalytic activity under direct sunlight. J. Photochem. Photobiol. A Chem. 2017, 346, 113-125. [CrossRef]

51. Martín-García, B.; Velázquez, M.M.; Rossella, F.; Bellani, V.; Diez, E.; Fierro, J.L.G.; Pérez-Hernández, J.A.; Hernández-Toro, J.; Claramunt, S.; Cirera, A. Functionalization of reduced graphite oxide sheets with a zwitterionic surfactant. ChemPhysChem 2012, 13, 3682-3690. [CrossRef] [PubMed] 
52. Singh, V.; Joung, D.; Zhai, L.; Das, S.; Khondaker, S.I.; Seal, S. Graphene based materials: Past, present and future. Prog. Mater. Sci. 2011, 56, 1178-1271. [CrossRef]

53. Xiao, J.; Mei, D.H.; Li, X.L.; Xu, W.; Wang, D.Y.; Graff, G.L.; Bennett, W.D.; Nie, Z.M.; Saraf, L.V.; Aksay, I.A.; et al. Hierarchically porous graphene as a lithium-air battery electrode. Nano Lett. 2011, 11, 5071-5078. [CrossRef] [PubMed]

54. Hu, J.; Li, H.S.; Muhammad, S.; Wu, Q.; Zhao, Y.; Jiao, Q.Z. Surfactant-assisted hydrothermal synthesis of $\mathrm{TiO}_{2} /$ reduced graphene oxide nanocomposites and their photocatalytic performances. J. Solid State Chem. 2017, 253, 113-120. [CrossRef]

55. Yang, Y.; Luo, L.J.; Xiao, M.; Li, H.; Pan, X.J.; Jiang, F.Z. One-step hydrothermal synthesis of surface fluorinated $\mathrm{TiO}_{2}$ /reduced graphene oxide nanocomposites for photocatalytic degradation of estrogens. Mater. Sci. Semicond. Process. 2015, 40, 183-193. [CrossRef]

56. Xu, Y.; Mo, Y.P.; Tian, J.; Wang, P.; Yu, H.G.; Yu, J.G. The synergistic effect of graphitic $\mathrm{N}$ and pyrrolic $\mathrm{N}$ for the enhanced photocatalytic performance of nitrogen-doped graphene/ $\mathrm{TiO}_{2}$ nanocomposites. Appl. Catal. B Environ. 2016, 181, 810-817. [CrossRef]

57. Chen, Z.P.; Ma, J.F.; Yang, K.; Feng, S.; Tan, W.S.; Tao, Y.X.; Mao, H.H.; Kong, Y. Preparation of S-doped $\mathrm{TiO}_{2}$-three dimensional graphene aerogels as a highly efficient photocatalyst. Synth. Met. 2017, 231, 51-57. [CrossRef]

58. Gu, Y.J.; Xing, M.Y.; Zhang, J.L. Synthesis and photocatalytic activity of graphene based doped $\mathrm{TiO}_{2}$ nanocomposites. Appl. Surf. Sci. 2014, 319, 8-15. [CrossRef]

59. Silva, C.G.; Faria, J.L. Photocatalytic oxidation of benzene derivatives in aqueous suspensions: Synergic effect induced by the introduction of carbon nanotubes in a $\mathrm{TiO}_{2}$ matrix. Appl. Catal. B Environ. 2010, 101, 81-89. [CrossRef]

60. Caridad, J.M.; Rossella, F.; Bellani, V.; Maicas, M.; Patrini, M.; Díez, E. Effects of particle contamination and substrate interaction on the Raman response of unintentionally doped graphene. J. Appl. Phys. 2010, 108, 085321. [CrossRef]

61. Caridad, J.M.; Rossella, F.; Bellani, V.; Grandi, M.S.; Díez, E. Automated detection and characterization of graphene and few-layer graphite via Raman spectroscopy. J. Raman Spectrosc. 2011, 42, 286-293. [CrossRef]

62. Ferrari, A.C.; Mayer, J.C.; Scardaci, V.; Casiraghi, C.; Lazzeri, M.; Mauri, F.; Piscanec, S.; Jiang, D.; Novoselov, K.S.; Roth, S.; et al. Raman spectrum of graphene and graphene layers. Phys. Rev. Lett. 2006, 97, 187401. [CrossRef] [PubMed]

63. Graf, D.; Molitor, F.; Ensslin, K.; Stampfer, C.; Jungen, A.; Hierold, C.; Wirtz, L. Spatially resolved Raman spectroscopy of single- and few-layer graphene. Nano Lett. 2007, 2, 238-242. [CrossRef] [PubMed]

64. Gupta, A.; Chen, G.; Joshi, P.; Tadigadapa, S.; Eklund, P.C. Raman scattering from high-frequency phonons in supported n-graphene layer films. Nano Lett. 2006, 6, 2667-2673. [CrossRef] [PubMed]

65. Casiraghi, C.; Hartschuh, A.; Lidorikis, E.; Qian, H.; Harutyunyan, H.; Gokus, T.; Novoselov, K.S.; Ferrari, A.C. Rayleigh imaging of graphene and graphene layers. Nano Lett. 2007, 7, 2711-2717. [CrossRef] [PubMed]

66. Sojoudi, H.; Baltazar, J.; Henderson, C.; Graham, S. Impact of post-growth thermal annealing and environmental exposure on the unintentional doping of CVD graphene films. J. Vac. Sci. Technol. B 2012, 30, 041213. [CrossRef]

67. Yang, R.; Huang, Q.S.; Chen, X.L.; Zhang, G.Y.; Gao, H.J. Substrate doping effects on Raman spectrum of epitaxial graphene on SiC. J. Appl. Phys. 2010, 107, 034305. [CrossRef]

68. Lin, S.S.; Chen, B.G.; Pan, C.T.; Hu, S.; Tian, P.; Tong, L.M. Unintentional doping induced splitting of G peak in bilayer graphene. Appl. Phys. Lett. 2011, 99, 233110. [CrossRef]

69. Ni, Z.H.; Yu, T.; Luo, Z.Q.; Wang, Y.Y.; Liu, L.; Wong, C.P.; Miao, J.M.; Huang, W.; Shen, Z.X. Probing charged impurities in suspended graphene using Raman spectroscopy. ACS Nano 2009, 3, 569-574. [CrossRef] [PubMed]

70. Berciaud, S.; Ryu, S.; Brus, L.E.; Heinz, T.F. Probing the intrinsic properties of exfoliated graphene: Raman spectroscopy of free-standing monolayers. Nano Lett. 2009, 9, 346-352. [CrossRef] [PubMed]

(C) 2018 by the authors. Licensee MDPI, Basel, Switzerland. This article is an open access article distributed under the terms and conditions of the Creative Commons Attribution (CC BY) license (http:/ / creativecommons.org/licenses/by/4.0/). 